\title{
A new photobioreactor for continuous microalgal production in hatcheries based on external-loop airlift and swirling flow
}

\author{
Karine Loubière ${ }^{1}$, Erell Olivo ${ }^{2}$, Gael Bougaran ${ }^{2}$, Jérémy Pruvost ${ }^{1,{ }^{*}}$, René Robert ${ }^{3}$, Jack \\ Legrand $^{1}$
}

\footnotetext{
${ }^{1}$ Laboratoire GEPEA UMR CNRS 6144, CRTT, Boulevard de I'Université, BP 406, 44602 Saint-Nazaire Cedex, France

${ }^{2}$ Laboratoire Physiologie et Biotechnologie des Algues, IFREMER Centre de Nantes, Nantes Cedex, France

${ }^{3}$ Laboratoire de Physiologie des Invertébrés, IFREMER, Station Expérimentale d'Argenton, Presqu'île du Vivier, Argenton en Landunvez, France
}

*: Corresponding author : Jérémy Pruvost, email address : jeremy.pruvost@univ-nantes.fr

\begin{abstract}
:
This study deals with the scale of a new photobioreactor for continuous microalgal production in hatcheries. The combination of the state-of-art with the constraints inherent to hatcheries has turned the design into a closed, artificially illuminated and external-loop airlift configuration based on a succession of elementary modules, each one being composed of two transparent vertical interconnected columns. The liquid circulation is ensured pneumatically (air injections) with respect to a swirling motion (tangential inlets). A single module of the whole photobioreactor was built-up to scale its geometry (diameter and length) and to optimize its design (air sparger, tangential inlets). The volumetric productivities were predicted by modeling radiative transfer and growth of Isochrysis affinis galbana (clone Tahiti). The hydrodynamics of the liquid phase was modeled in terms of global flow behavior (circulation and mixing times, Péclet number) and of swirling motion decay along the column (Particle Image Velocimetry). The aeration performances were determined by overall volumetric mass transfer measurements. Continuous cultures of Isochrysis affinis galbana (clone Tahiti) were run in two geometrical configurations, generating either an axial or a swirling flow. Lastly, the definitive options of design are presented as well as a 120-L prototype, currently implemented in a French mollusk hatchery and commercialized.
\end{abstract}

Keywords: continuous photobioreactor $\bullet$ hatchery $\bullet$ airlift $\bullet$ swirling flow $\bullet$ Isochrysis affinis galbana

\section{INTRODUCTION}

With regard to their taxonomic diversity and plasticity, photosynthetic microorganisms are a natural resource with high potential, thus attracting scientific and industrial attention. Their development can be separated into either, direct use of biomass or indirect use for the 
production of high-value compounds and for environmental applications (wastewater treatment, hydrogen or biodiesel production) (Richmond 2004, Spolaore et al 2006). Their production under controlled conditions implies a specific reactor, named photobioreactor, which mainly differs from classical bioreactors by the need of a light supply, these microorganisms being photoautotrophic. Light cannot be considered as a common substrate insofar as it involves two antagonist phenomena: on the one hand, a high amount of photonic energy is required to ensure microalga growth conditions, but on the other hand, the increase of the biomass concentration in the reactor decreases the light penetration depth in the culture due to cell self-shading. Thus, the use of light in the culture is the major constraint in photobioreactors, which makes their scale-up difficult and often limits the production of concentrated biomass with high quality and productivity. The literature describes a great diversity of photobioreactors, often classified into plane and cylindrical/tubular geometrical configurations (Carvalho et al 2006), showing that no a priori ideal geometry exists.

In the present study, the application targeted is aquaculture and more particularly mollusk hatcheries. Microalgae are here used to feed broodstock, larvae and spat, and have then to be regularly produced in large amounts (Coutteau and Sorgeloos 1992). According to a survey that we have conducted in the main six hatcheries of the French West Coast, microalgal production represented in 2002, for flagellate microalgae, from 400 to 6,000 billions cells per day, and for diatoms, from 900 to 20,000 billions cells per day. The microalgae commonly cultivated for mollusks are Isochrysis affinis galbana, Pavlova lutheri, Chaetoceros muelleri, Chaetoceros calcitrans, Thalassiosira pseudonana, Skeletonema marinoï (Borowitzka, 1997). For Pacific cupped oyster Crassostrea giga larvae, a bi-specific diet is rather privileged for the youngest larvae: Isochrysis affinis galbana is then associated with a complementary microalga which is different from one hatchery to another (Rico-Villa et al 2006). At present, microalgal production in French hatcheries is mainly performed by means of batch culture 
systems consisting of vertical aerated column PMMA reactors. Their major drawbacks are a partial control of biomass quality and quantity, low productivities, contamination, manpower intensive (frequent handling and cleaning operations), biofouling.

To improve this situation, the present work proposes a new photobioreactor for continuous microalgal production in hatcheries. The constraints to integrate for the design are: to ensure a continuous production adjustable to hatchery requirements, to be a closed and artificially illuminated system, to have a design as simple as possible for minimizing fabrication cost, price and floor-space, to be robust (marine atmosphere) and easy to clean. From that, a preliminary choice of geometrical configuration has been realized: it consists of a succession of elementary modules, each one being composed of two transparent vertical interconnected columns. The liquid phase circulation is performed pneumatically, namely by gas injections placed at the column bottom and uniformly dispatched in the whole photobioreactor. Thus, each elementary module can be seen as an external loop airlift photobioreactor, except that the outlet of the downcomer is connected to the next module. In addition, as already used in annular (Pruvost et al 2002, Muller-Feuga et al 2003a, Muller-Feuga et al 2003b) and torus photobioreactors (Pottier et al 2005), a swirling motion will be generated (tangential inlets) in order to minimize the biofilm formation at walls. The major interest of this design is not only to enable closed, artificially-illuminated and continuous microalgal culture to be easily performed, but also modularity in volume to be satisfied without scaling-up/down calculations. Indeed, the illumination device will be designed so as to conserve the same illuminated specific surface (ratio of the illuminated surface to the culture volume) whatever the numbers of modules, implying that, for a given incident flux and a fixed dilution rate, the volumetric productivity will remain identical for a single module and for a multimodule photobioreator. As a consequence, the number of elementary modules will only be conditioned by the microalgal production required. This is an essential advantage with regard 
to the variability of hatchery sizes and phytoplankton productions.

This study reports results of various investigations carried out to scale the geometry of this photobioreactor (column diameter and length) and to optimize its design (air sparger, tangential inlets). A single module of the whole photobioreactor is built up to test the influence of various parameters. The column diameter constitutes a key parameter as controlling the light distribution inside the culture: it will be chosen in accordance with the predictions of volumetric productivities (coupled modeling of radiative transfer and photosynthetic growth). The column height is mainly dependent on the decay of swirling motion along the column and on its efficiency to limit biofouling at walls; that is why the effects of air flow rate, air sparger and tangential inlets on hydrodynamics will be investigated (tracing, PIV). Moreover, the aeration performances will be determined by overall volumetric mass transfer measurements. Lastly, continuous cultures of the microalga Isochrysis affinis galbana (clone Tahiti) will be run in two geometrical configurations, generating either an axial or a swirling motion; they will enable the volumetric productivities and the biofouling deposited to be compared. In conclusion, the definitive options of design will be expressed and a 120-L prototype presented.

\section{MATERALS AND METHODS}

\section{Description of the experimental set-up}

The single-module photobioreactor consists of an external-loop airlift made of transparent PMMA to allow effective light penetration and a clear visual observation (Figure 1a). This device is composed of two vertical columns connected by two flanges, the column above the air sparger being called the riser and the other one the downcomer. Liquid circulation is induced by the hydrostatic unbalance caused by the density difference between the gassed and ungassed liquid columns. These columns are of equal sizes with a 0.03 m radius $R$, a $1 \mathrm{~m}$ 
liquid height $H_{L}$. The total liquid volume $V_{L}$ is $6.1 \mathrm{~L}$. Note that the downcomer column is machined in a cubic transparent block to minimize optical distortion for PIV measurements. The swirling motion is induced by tangential inlets inside each column (Legentilhomme and Legrand 1991). For that, specific connection flanges are designed by means of prism-shaped inserts of different sizes introduced in the body of the flange (Figure 1b). The three geometrical configurations of flanges investigated are characterized by Velocity Factors $V F$ equal to 1, 4 and 9, where VF1 generates an axial motion inside columns (no prism insert). This latter parameter, $V F$, is defined as the ratio of the injection velocity at the flange outlet to the mean velocity at the flange inlet (Legentilhomme and Legrand 1991), namely between the sections at the flange inlet and outlet (Figure 1c).

Two air spargers are tested (Figure 1a): a capillary (2 mm in diameter) located tangentially to the wall of the riser base (noticed T), and an elastic multi-perforated membrane recovering the entire column section (denoted $\mathrm{M}$ ). The air flow rates $Q_{G}$ vary between 0.1 and 1.6 NL.min ${ }^{-1}$. The superficial velocities $U_{G}$ are then very low, ranging from 2.2 to $9.4 \mathrm{~mm} . \mathrm{s}^{-1}$. The associated specific power input in the reactor $P_{G} / V_{L}$ (Chisti, 1989) varies from 11 to 43 W. $\mathrm{m}^{-3}$. Note that no bubbles are observed in the downcomer and that the average gas hold-up is always below $1 \%$ (qualitative measurements).

\section{Hydrodynamics of the liquid phase}

Tracer measurements. A pulse of tracer (seawater) is injected in front of the inlet of the lower connection flange, and is detected by a platinum conductimetric probe located inside this flange, flushed with wall. The variation in conductance, directly proportional to tracer concentration, is measured by a conductimeter Tacussel ${ }^{\circledR}$ CD810 coupled with a data acquisition device and a computer. These tracer experiments are performed in water, for three Velocity Factors (VF1, VF4, VF9), for both air spargers and for seven gas flow rates.

Particle Image Velocimetry. This technique is applied to characterize the swirling motion and 
its decay along the downcomer height where no bubble entrainment occurs. A Dantec ${ }^{\circledR}$ device is used with a laser Nd-YAG New Wave Solo (15 mJ/pulse). The light pulses are synchronized with a CCD camera (Dantec Dynamics Flow Sense M2/E 8 bits, 1600×1186 pixels $^{2}$ ) equipped with an objective Nikon $60 \mathrm{~mm}$. These images are analyzed with the Flow Manager ${ }^{\circledR}$ software to obtain velocity fields. The tracer is made of polyamide particles (Dantec Invent ${ }^{\circledR}$ 38A2121) with a mean diameter of $50 \mu \mathrm{m}$ (concentration close to 0.1 g.L $\mathrm{L}^{-1}$ ). The image calibration is ensured by using sighting marks placed inside the downcomer whose dimensions are known. To determine the swirl intensity, instantaneous velocity fields are measured, inside the downcomer, in $r x$-planes (Figure 2) at different radial positions ( $r$ equal to $-0.025,-0.02,-0.01,0,0.01,0.02$ and $0.025 \mathrm{~m}$ ) and axial positions ( $x$ equal to $0.05,0.15$, 0.25, 0.4, 0.55 and $0.85 \mathrm{~m}$ ). For a given operating condition, an average of 200 image acquisitions is required to calculate time-averaged velocity fields. The image post-treatment is equivalent to the one performed by Pruvost et al (2000). Finally, the radial profiles of axial and tangential components of time-averaged velocity (noted $U(r)$ and $W(r)$ respectively) are obtained at different heights, $x$, in the downcomer. It is important to precise that, according to the measurement planes, the tangential component of velocity, $W$, can be only known in the vertical symmetrical plane of the downcomer (Pruvost et al 2000). In Figure 2a, the locations where they are calculated are represented by black points. In practice, for one given axial position $x$, the radial profiles of tangential components, $W(r)$, are reconstructed from data measured in the $r x$-planes acquired at different radial positions $r$ (Figure 2a). These PIV experiments are carried out in seawater, for two Velocity Factors (VF4, VF9), both air spargers and two gas flow rates $\left(Q_{G}=0.74\right.$ and 1.6 NL.min $\left.{ }^{-1}\right)$.

\section{Gas-Liquid mass transfer}

The well-known dynamic gassing-in and gassing-out method is used to measure overall volumetric gas-liquid mass transfer coefficients $k_{L} a$ (Roustan 2003). After removing oxygen 
from the liquid phase (nitrogen bubbling), air flow is established and the time-variation of $C_{L}$ followed, until saturation, by means of an oxygen probe (Mettler Toledo® $\mathrm{O}_{2}$ InPro 6800) placed at the top of the downcomer column and connected to a transmitter (Mettler Toledo® $\mathrm{O}_{2}$ InPro 4100). During this reoxygenation step, the mass balance in dissolved oxygen concentration is:

$\frac{\mathrm{d} C_{L}}{\mathrm{~d} t}=k_{L} a\left(C_{L}^{*}-C_{L}\right)$

where $C_{L}^{*}$ is the dissolved oxygen concentration at saturation (at $25^{\circ} \mathrm{C}$ and at the oxygen partial pressure in air under atmospheric pressure, it is equal to $8.3 \mathrm{mg} . \mathrm{L}^{-1}$ for tap water and to $6.9 \mathrm{mg} . \mathrm{L}^{-1}$ for seawater and Conway medium). The dynamics of the oxygen probe can be described using a first-order differential equation (Ingham et al 1994) as:

$$
\frac{\mathrm{d} C_{p}}{\mathrm{~d} t}=\frac{1}{t_{p}}\left(C_{L}-C_{p}\right)
$$

where $C_{p}$ is the dissolved oxygen concentration inside the probe. The time constant of the oxygen probe, $t_{p}$, is measured using a method based on probe response to negative oxygen steps (Vandu et al 2004), and found equal to $14 \mathrm{~s}$. This latter value is negligible when compared to mass transfer characteristic times, $1 / k_{L} a$, the minimum of which is here $73 \mathrm{~s}$.

Finally, the overall volumetric mass transfer coefficient is accurately determined by solving the following equation resulting from the combination of Eq. (1) with Eq. (2):

$$
\frac{C_{p}}{C_{L}^{*}}=1+\left(\frac{\exp \left(-k_{L} a \cdot t\right)-k_{L} a \cdot t_{p} \cdot \exp \left(-t / t_{p}\right)}{k_{L} a \cdot t_{p}-1}\right)
$$

The mass transfer experiments are run for three liquid phases (tap water, seawater, Conway medium), three Velocity Factors (VF1, VF4, VF9), both air spargers and five gas flow rates. For all these conditions, the usual assumptions associated with Eq. (1) (i.e. a perfectly mixed liquid phase, a constant gas composition between the reactor inlet and outlet) are verified. 


\section{Algal cultures}

Microalga and culture medium. Because it is used in French mollusk hatcheries, Isochrysis affinis galbana (clone Tahiti) is selected for this study. Under the reference CCAP 927/14, it was obtained from the phytoplanktonic collection of Oban (Scotland). The algal nutritive medium consists of natural seawater (originated from the coastal area of Saint-Malo in France, aged in the dark during one month, filter-sterilized through a $0.22 \mu \mathrm{m}$ pore-size filter) enriched in Conway medium at $1 \mathrm{~mL}$ per Liter of seawater (Table 1).

Growth curve. The growth curve of the microalga Isochrysis affinis galbana, $\mu(G)$, has to be determined for predicting productivity. For that, the planar torus photobioreactor described by Pottier et al (2005) and Pruvost et al (2006) is used. The cultures are run in turbidostat mode. A low cellular concentration $\left(10^{9}\right.$ cell. $\left.\mathrm{L}^{-1}\right)$ is maintained to minimize the effects of mutual shading. Indeed, to display accurate results, it is important to differentiate the incident light, $q_{O}$, measured behind the reactor surface from the averaged irradiance, $G$, really received by the culture. Knowing cell concentration inside the reactor, $G$ is calculated by integrating, along the culture depth $z$, the attenuation profile of irradiance predicted by the radiative transfer model (see Theoretical Developments below). As a very low concentration is maintained in the torus reactor, the incident and averaged lights is very close, and thus the potential error induced by the model becomes negligible.

This torus photobioreactor is illuminated by a set of 10 daylight fluorescent tubes (OSRAM L13W/12-950, diameter $16 \mathrm{~mm}$ ), fixed on a framework to keep them parallel. For a given distance between light source and torus reactor, the incident light flux $q_{O}$ is measured, without microalgal culture, behind the front surface of the reactor, by means of a spherical quantum sensor (LICOR US-SQS/A Heinz Walz). Four measurement points are considered to calculate an average value of $q_{o}$. Once the culture has reached equilibrium, the averaged growth rate $<\mu>$ is determined, and according to previous comments, can be associated to the real 
irradiance $G$ received by microalgae. The Isochrysis affinis galbana growth curve is here established for $q_{O}$ ranging from 15 to $400 \mu \mathrm{mol} . \mathrm{m}^{-2} . \mathrm{s}^{-1}$.

Continuous cultures. The single-module photobioreactor is sterilized by a peroxyacetic acid solution (5\%, $20 \mathrm{~min})$. The microalgal inoculum leads to an initial concentration close to $10^{9}$ cell. $\mathrm{L}^{-1}$. Continuous cultures are run in chemostat mode: a KNF Stepdos ${ }^{\circledR}$ pump is used for medium renewal while the culture is harvested by overflowing. Isochrysis affinis galbana cultures are run in two geometrical configurations to compare biological performances using an axial or a swirling motion. Thus, two identical pilots are used simultaneously: the first is equipped with VF1-shaped flanges and the second with VF4-shaped flanges. Apart from VF, the other conditions are similar. The dilution rate $D$ is set to $0.36 \mathrm{~d}^{-1}$, but daily controlled. The temperature is regulated at $27 \pm 1^{\circ} \mathrm{C}$ (thermoregulated room), and the $\mathrm{pH}$ maintained at $7.2 \pm$ 0.1 by automatic injection of $\mathrm{CO}_{2}$ (solenoid valve). The average incident light flux $q_{O}$ on the reactor surface is equal to $250 \pm 10 \mu \mathrm{mol} \cdot \mathrm{m}^{-2} \cdot \mathrm{s}^{-1}$. The air sparger is the capillary located tangentially to the wall of the riser base, and the air flow rate is fixed at $1.4 \mathrm{NL} \cdot \mathrm{min}^{-1}$. Cell concentration, $X$, is daily measured by cellular counting (Malassez cell), as well as the nitrate and phosphate residual concentrations (ionic chromatography) to verify that no substrate limitation occurs. For each VF condition, the continuous cultures are run three times. Lastly, the volumetric productivity $P_{X}$ is calculated by the product between $X$ and $D$ at equilibrium. To compare both configurations, the biofouling at walls is also visually observed.

Radiative-field measurements. The single-module photobioreactor is illuminated by 10 fluorescent tubes (Grolux ${ }^{\circledR}$ F58W/GRO-T8, Sylvania Co.), horizontally disposed and spaced $12 \mathrm{~cm}$ from each other. For different distances between reactor and tubes, the incident light flux $q_{O}$ behind the curved surface of the reactor is measured as a function of the angular position $\theta_{C}$ (from $-\pi / 2$ to $\pi / 2$ ). These measurements are performed, without culture, by using a spherical quantum sensor (LICOR US-SQS/A Heinz Walz, $3 \mathrm{~mm}$ in diameter), and will serve 
as initial conditions in the light transfer modeling (see Theoretical Developments below). Moreover, the attenuation profile of irradiance is experimentally determined for $X=1.7 .10^{10}$ cell. $\mathrm{L}^{-1}$ and for $q_{O}=210 \mu \mathrm{mol} \cdot \mathrm{m}^{-2} . \mathrm{s}^{-1}$. For these experiments, the underwater spherical quantum sensor is displaced radially inside the column (with an increment equal to $4.5 \mathrm{~mm}$ ), and a black shield is placed around the column half circumference opposite the light source to avoid wall reflections.

\section{THEORETICAL DEVELOPMENTS}

\section{Productivity prediction and Radiative transfer modeling}

In steady state regime, the volumetric microalgal productivity, $P_{X}$, is expressed as:

$P_{X}=<\mu>X=D X$

where $\langle\mu\rangle$ is the average growth rate. For photosynthetic growth, $\mu$ depends on the irradiance received $G$. Both absorption and scattering phenomena led to heterogeneous radiative field inside the culture. Therefore, knowing $<\mu>$ imposes to calculate the attenuation profile along the culture depth, $G(z)$. The coupling with Isochrysis affinis galbana growth curve then enables the local growth kinetics $\mu(G(z))$ and so $<\mu>$ to be determined.

As in Cornet et al (1995) and in Pottier et al (2005), a two-flux formulation of the general theory of radiative transfer is used to determine the irradiance field. Based on an onedimensional light attenuation hypothesis, the light propagation is considered along a unique axis, $z$, but in two opposite directions to take into account the backward scattering part of light flux $\left(I^{-}\right)$. Assuming a quasi-collimated field of radiation and a normal incidence, the set of differential equations to solve is:

$$
\begin{aligned}
& \frac{\mathrm{d} I^{+}}{\mathrm{d} z}=-E_{a} X I^{+}-b E_{s} X\left(I^{+}-I^{-}\right) \\
& \frac{\mathrm{d} I^{-}}{\mathrm{d} z}=E_{a} X I^{-}-b E_{s} X\left(I^{+}-I^{-}\right)
\end{aligned}
$$


Note that, even though the previous assumptions are not really verified in the present case (external and quite diffused illumination), this approach will be conserved insofar as the aim is just to use the light transfer modeling as a tool to pre-design the multimodule photobioreactor. Once the boundary conditions defined, the resolution of Eq. (5) leads to $I^{+}$ and $I^{-}$, and thus to the irradiance $G$ at a given culture depth $z$ as:

$G(z)=I^{+}+I^{-}$

In contrast to the planar torus photobioreactor of Pottier et al (2005), the present airlift geometry has a cylindrical-shaped surface. In this case, due to refraction effects induced by curvature, the direction of the incident light flux is no more unique: when passing across the curvature, light rays are deviated from their initial direction. This phenomenon has been integrated into the light transfer modeling of Pottier et al (2005), by considering: (i) the distribution of incident light flux at the curvature boundaries, $q_{o}\left(\theta_{C}\right)$ (see Material and Methods above), (ii) the Fresnel-Descartes law to calculate, for each incident light ray impinging the reactor optical surface, its new direction $z$ inside the culture and the associated light path length $L$. The refraction phenomenon leads to intersections inside the culture between several light directions: the resulting irradiance is then calculated as the sum of irradiances obtained at the intersection point.

The boundary conditions linked to Eq. (5) depend on light conditions and reactor geometry. As, in the single-module photobioreactor, the front optical side is illuminated and the back optical side is transparent, they are written, if $L$ is the light path length, as:

$$
\begin{array}{ll}
Z=0: & I^{+}=q_{o}\left(\theta_{C}\right) \\
Z=L: & I^{-}=0
\end{array}
$$

Lastly, the irradiance profile along each ray direction is expressed by the analytical solution:

$$
G(z)=2 q_{O}\left(\theta_{C}\right) \frac{(1+\alpha) \cdot \exp (\delta(L-z))-(1-\alpha) \cdot \exp (-\delta(L-z))}{(1+\alpha)^{2} \cdot \exp (\delta L)-(1-\alpha)^{2} \cdot \exp (-\delta L)}
$$


where, $\quad \alpha=\sqrt{\frac{E_{a}}{\left(E_{a}+2 b E_{s}\right)}}, \quad \delta=\left(E_{a}+2 b E_{s}\right) \alpha X$

The accurate formulation of this radiative transfer model needs to determine the optical properties of the culture. Pottier et al (2005) computed the optical properties of the microalga Chlamydomonas reiinhardtii, by means of a powerful predictive method based on the LorenzMie theory and on a preliminary knowledge of microalga pigment contents, size and shape. The same approach is applied here for Isochrysis affinis galbana by considering a mean diameter of $5 \mu \mathrm{m}$, a mean cellular mass of $7.64 \mathrm{pg}$ and an ovoid shape (image analysis). Issued from literature data (Green and Leadbeater 1994), the pigment composition (weighted percent) is: chlorophyll-a $2 \%$, chlorophyll-b $0 \%$, chlorophyll-c $0.6 \%$, photoprotective carotenoids (fucoxanthine, diadinoxanthine, diatoxanthine, caroten) 2.4\%. Finally, the optical properties of Isochrysis affinis galbana are the following:

$$
E_{a}=293 \mathrm{~m}^{2} \cdot \mathrm{kg}^{-1} \quad E_{s}=757 \mathrm{~m}^{2} \cdot \mathrm{kg}^{-1} \quad b=0.01162
$$

\section{Global flow modeling}

From tracer measurements, the hydrodynamic behavior is modeled by an axial dispersed plug flow with total recirculation, thereby enabling the mean circulation time $t_{C}$ and the axial dispersion coefficient $D_{a x}$ to be determined. This model, commonly used in the case of swirling flows (Benkhelifa et al 2000), is expressed by:

$$
\frac{C(\theta)}{C_{\infty}}=\frac{1}{2} \sqrt{\frac{P e_{L}}{\pi \theta}} \sum_{j=-\infty}^{+\infty} \exp \left(-\frac{P e_{L}\left(j+z^{*}-\theta\right)^{2}}{4 \theta}\right)
$$

The mean circulation time, $t_{C}$, is optimized, as well as the Péclet number $P e_{L}$ and the geometrical factor $z^{*}$, by fitting Eq. (11) with the experimental curve using the Nelder-Mead algorithm. The optimization is considered valid if the mean standard deviation (between calculated and experimental responses) is between 0.05 and 0.1 . The mean circulation velocity, $U_{C}$, is then calculated by: 


$$
U_{C}=\frac{L_{t}}{t_{C}}
$$

The mixing time $t_{m}$ is defined with respect to a homogeneity degree equal to $95 \%$.

\section{Characterization of swirling decaying flows}

Even if swirling decaying flows are extremely complex (three-dimensional, non-axisymmetrical and non-established with regard to the axial position), the swirl intensity can be quantified according to the swirl number Sn. This dimensionless parameter represents the axial flux of swirl momentum divided by the product between the axial flux of axial momentum and the column diameter (Gupta et al 1984), and is given by:

$$
S n=\frac{\int_{-R}^{R} U W r^{2} \mathrm{~d} r}{2 R \int_{-R}^{R} U^{2} r \mathrm{~d} r}
$$

It is particularly useful to study the decay of the swirling motion with the axial position from the swirl inducer, this decay is often correlated by an empirical exponential law as:

$$
S n=a^{\prime} \exp \left(\frac{-b^{\prime}}{2 R}\right)
$$

where $a^{\prime}$ et $b$ ' are empirical coefficients linked to the initial swirling intensity and the motion decay respectively.

\section{RESULTS AND DISCUSSION}

\section{Theoretical productivity}

Validation of the radiative transfer modeling. For $q_{O}=210 \mu \mathrm{mol} \cdot \mathrm{m}^{-2} \cdot \mathrm{s}^{-1}$ and $X=1.7 \cdot 10^{10}$ cell. $L^{-1}$, Figure 3 reports the predicted attenuation profiles along the culture depth with the measured irradiances. The integration of refraction effects in the modeling is positive: a better agreement between experimental and predicted irradiances occurs when optical distortion is considered. Although the model tends to underestimate the attenuation at the back optical 
side, these results are widely acceptable, especially with regard to the geometrical complexity (curved surface) and the simplifying assumptions emitted (collimated incident light, approximate optical properties). Figure 4 gives an example of predicted irradiance fields over the column section whether refraction effects are considered or not. Important differences are highlighted: light ray refraction slows down light dilution inside the culture and reduces the proportion of slightly illuminated zones. This is directly linked to the irradiance overconcentrations generated near walls on light source side. Such results are in agreement with the attenuation profiles observed in Figure 3.

Isochrysis affinis galbana growth curve. The experimental specific growth rates $\mu$ of Isochrysis affinis galbana are reported in Figure 5 as a function of the irradiance received $G$. As no photoinhibition is experimentally observed below $360 \mu \mathrm{mol} . \mathrm{m}^{-2} . \mathrm{s}^{-1}$, a simple model based on a Monod law is chosen to describe the growth curve:

$\mu=\mu_{\max } \frac{G}{K_{G}+G}-\mu_{m}$

Calculated by a multi-parametric regression based on experimental data, these parameters are: $\mu_{\max }=3.12 \mathrm{~d}^{-1}, \mu_{m}=0.93 \mathrm{~d}^{-1}, K_{G}=25.6 \mu \mathrm{mol} \cdot \mathrm{m}^{-2} \cdot \mathrm{s}^{-1}$. The compensation irradiance $G_{C}$ (determined from Eq. (15) when $\mu=0$ ) is then equal to $10.9 \mu \mathrm{mol} \cdot \mathrm{m}^{-2} \cdot \mathrm{s}^{-1}$. The latter value is rather in agreement with literature: Falkowski et al (1985) found $G_{C}$ equal to $16 \mu \mathrm{mol} . \mathrm{m}^{-2} . \mathrm{s}^{-1}$, Molina Grima et al (1997) to $10 \mu \mathrm{mol} \cdot \mathrm{m}^{-2} \cdot \mathrm{s}^{-1}$ and Tzovenis et al (2003) to $8 \mu \mathrm{mol} . \mathrm{m}^{-2} . \mathrm{s}^{-1}$. Molina Grima et al (1997) determined a maintenance term $\mu_{m}$ close to the present one, $0.92 \mathrm{~d}^{-}$ ${ }^{1}$ versus $0.93 \mathrm{~d}^{-1}$ respectively. Nevertheless, an important variability is observed for the inhibiting irradiance: although no photoinhibition appears here, Sukenik and Wahnon (1991) have reported that Isochrysis affinis galbana is saturated at $300 \mu \mathrm{mol} . \mathrm{m}^{-2} . \mathrm{s}^{-1}$ and inhibited at $500 \mu \mathrm{mol} . \mathrm{m}^{-2} . \mathrm{s}^{-1}$; according to Molina Grima et al (1997), the growth optimum varies from 820 to $1620 \mu \mathrm{mol} . \mathrm{m}^{-2} . \mathrm{s}^{-1}$, the photoinhibition occuring over. These results remain difficult to interpret and to compare because: (i) light measurement methods are different and/or not 
precised, (ii) the time during which microalgae are submitted to a given incident flux is not well defined, (iii) the light flux considered is often the one emitted by light source or measured at the reactor surface and not the irradiance really received by microalgae.

Predicted productivity. The microalgal productivity is predicted according to Eq. (4) where $<\mu>$ is the average of the local growth kinetics, $\mu(G(z))$, solved by coupling the two-flux radiative transfer model, Eqs. (5-10), and the Isochrysis affinis galbana growth curve, Eq. (15). Figure 6a reports, for $q_{O}=250 \mu \mathrm{mol} \cdot \mathrm{m}^{-2} \cdot \mathrm{s}^{-1}$, the predicted productivity, $P_{X}$, as a function of dilution rate, $D$, and of the column radius, $R$. Whatever the column radius, the variation looks similar and is characterized by an optimum obtained for a dilution rate $D$ close to 0.035 $\mathrm{h}^{-1}\left(0.84 \mathrm{~d}^{-1}\right)$. These optimal volumetric productivities result from an equilibrium maximizing both cell concentration and culture harvest flow rate. They are very sensitive to the column radius, a drastic decrease being observed for increasing radii. Figure $6 \mathrm{~b}$ presents, at the dilution rate chosen for experiments $\left(D=0.36 \mathrm{~d}^{-1}\right)$, the variations of the volumetric productivity with the column radius, for three incident light flux. It clearly appears that, especially for low radii, the incident light flux has a major influence: for $R=0.03 \mathrm{~m}, P_{X}$ is close to $3.0 .10^{10}$ cell. $\mathrm{L}^{-1} \cdot \mathrm{d}^{-1}$ for $250 \mu \mathrm{mol} . \mathrm{m}^{-2} . \mathrm{s}^{-1}$, to $2.5 \cdot 10^{10}$ cell. $\mathrm{L}^{-1} \cdot \mathrm{d}^{-1}$ for $200 \mu \mathrm{mol} . \mathrm{m}^{-2} . \mathrm{s}^{-1}$ and to $1.5 \cdot 10^{10}$ cell. $\mathrm{L}^{-1} \cdot \mathrm{d}^{-1}$ for $100 \mu \mathrm{mol} \cdot \mathrm{m}^{-2} \cdot \mathrm{s}^{-1}$.

For designing the multimodule photobioreactor, these predictions are very useful: knowing the daily larval needs in microalgae, the photobioreactor volume theoretically required can be easily calculated for each column radius and incident light flux. A survey has been conducted in the main six hatcheries of the French West Coast (all being devoted to the Pacific cupped oyster Crassostrea gigas). The data collected have shown that the production of Isochrysis affinis galbana required is close to $1.2 .10^{12}$ cell. $\mathrm{d}^{-1}$ (this is an average value which can significantly vary depending on hatchery sizes). Using these data, the photobioreactor volume theoretically required is ranging from 50 to $130 \mathrm{~L}$ (for $2<R<5 \mathrm{~cm}$ and $100<q_{O}<200$ 
$\left.\mu \mathrm{mol} . \mathrm{m}^{-2} . \mathrm{s}^{-1}\right)$. It increases for increasing radii and for decreasing incident flux. Using low column radii offers, on the one hand, the undeniable advantage to reduce the photobioreactor volume (higher productivities), but on the other hand, presents the drawback to multiply the number of columns and connection flanges, which is economically disadvantageous. These results indicate that the optimal column diameter should be mainly chosen from a compromise between productivity and building cost prices, even though other factors, such as floor-space or cleaning simplicity, should also be taken into account. Finally, the complete integration of various parameters converges towards a column radius equal to $0.03 \mathrm{~m}$ (study not detailed).

\section{Hydrodynamics of the liquid phase}

The aim being to design a multimodule photobioreactor for hatcheries, no advanced modeling on hydrodynamics will be proposed here: the investigations will therefore be restricted to the characterization of the global flow behavior and of the swirling motion decay. Note that comparisons with literature on airlift reactors will remain, in general, difficult because the characteristics of the present airlift are original: very low superficial gas velocity (below 1 $\mathrm{cm} . \mathrm{s}^{-1}$ ), external-loop with columns of equal sizes, swirling motion.

Global flow behavior. In Figure $7 \mathrm{a}$, the mean circulation velocities $U_{C}$ are plotted as a function of superficial gas velocity $U_{G}$, for several Velocity Factors and air spargers. They are significantly larger when the motion inside the reactor is axial rather than swirling, or in other words, when the Velocity Factor decreases. This is directly linked to the increase of pressure drops due to section restrictions inside the connection flanges. When compared to Velocity Factor, the kind of air spargers has a minor influence on the mean circulation velocities: the membrane sparger (M) tends to generate slightly higher velocities than the capillary located tangentially to the column (T), probably resulting from larger gas retentions. As in Chisti (1989), the previous variations of $U_{C}$ with $U_{G}$ can be described by an empirical relation based on a power law (see Table 2). 
The mean circulation times, $t_{C}$, are reported in Table 2 . They clearly highlight how the swirling flow enables the time necessary for fluid to cover one reactor loop to be significantly increased, when compared to a purely axial motion. In Table 2 are also reported the ratios, averaged over the range of gas velocity, of mixing time to mean circulation time. They decrease for increasing Velocity Factors: generating a swirling flow, instead of an axial one, then enables the number of loops necessary to reach a perfectly mixed state to be reduced. The mixing ability of the reactor is thus enhanced thanks to swirling motion.

Figure $7 \mathrm{~b}$ presents the Péclet number (defined on the mean reactor length) as a function of the superficial gas velocity. Whatever the conditions, no noticeable variation of Péclet number with gas velocities is observed. In contrast, the Velocity Factor induces a significant decrease of $P e_{L}$ (or a rise of the axial dispersion coefficient $D_{a x}$, see Table 2) with increasing VF. This shows that the motion behavior goes from a plug type flow ( $P e_{L}>100$ for $\left.V F 1\right)$ to a mixed type flow, thus confirming thus that swirling motion enables the mixing to be improved.

Swirling flow characterization. First of all, for each operating condition, it has been verified that, when the radial profiles of axial velocity components are integrated along the column diameter, the mean circulation velocity deduced is conserved whatever the axial positions, and is equal to the one calculated by tracer measurements (Eq. 12). These calculations make the velocity field measurements valid, even if they have been only performed for a single angular position $\theta_{C}$.

Figures 8a and 8b plot typical radial profiles of velocity components at different axial positions. These curves illustrate that the main movement responsible for swirling motion is controlled by the tangential component, which decreases with increasing axial positions but always remains greater than the axial component. The latter observation is particularly important to prove that the designed tangential inlets are efficient to generate a swirling flow along the full column height. As already observed in annular photobioreactors using swirling 
flows (Pruvost et al 2000), the extremes of both axial and tangential velocities are located near the walls and tend to shift towards the center of the column for increasing axial positions. This is explained by the centrifugal force effects induced by the tangential inlet that diminish as far as the distance from the connection flange increases. In contrast to annular configurations, negative axial velocities are present in the central area of the column, giving evidence of flow recirculations. They are highly pronounced at the top of the column and disappear more downstream; their existence enables the increase of tangential component generated by the centrifigal force to be counterbalanced (Aoubed et al 1994). Note that, when air flow rate increases, all these behaviors are conserved or become acute (data not reported). Lastly, the comparison between Figures $8 \mathrm{a}$ and 8b logically shows that smaller axial components and greater tangential components are obtained for VF9 than for VF4

The curves of the swirl number $S n$ as a function of the axial position $x$ are given in Figure 9 . As aforementioned (Figure 8), the attenuation of the swirling motion is here clearly demonstrated whatever the operating conditions. It is essential to note that this decay is significant at the bottom of the column but not complete. Except near the tangential inlet, no major difference is found between both Velocity Factors and air flow rates. As a consequence, the decay of the swirling motion is modeled by a unique exponential law with $a^{\prime}=0.920$ and $b^{\prime}=0.086$ (Eq. 14).

The conclusion to be drawn from these results is that, independently of air sparger and air flow rate, both Velocity Factors, VF4 and VF9, ensure the conservation of swirling motion along the full column height. The attenuation being yet significant, it seems more reasonable to impose, for the multimodule photobioreactor, a column height which does not exceed $1 \mathrm{~m}$.

\section{Gas-liquid mass transfer}

The variations of the volumetric gas-liquid mass transfer coefficient with the superficial gas velocity are plotted in Figure 10 with tap water as liquid phase. Whatever the operating 
conditions, $k_{L} a$ can be correlated with $U_{G}$ according to a power law (Wu and al 1992):

$k_{L} a=\beta \cdot U_{G}^{\delta}$

The values of the empirical coefficients, $\beta$ and $\delta$, are reported in Table 3. Beyond this, it is interesting to note that, whatever the Velocity Factors, the membrane sparger (M) induces volumetric mass transfer coefficients two to three times higher than the capillary sparger $(\mathrm{T})$. This is directly related to the fact that the membrane sparger generates smaller bubble sizes and higher gas retentions than the capillary one, thus producing higher interfacial areas. The mass transfer performances of such a sparger are widely recognized (Hébrard et al 1996, Loubière et al 2003) and are here reinforced by the fact that all the bubbles formed at the exit of the membrane orifices are collected under the influence of the swirling motion inside an air column which, about twenty centimeters above, bursts into a swarm of very small spherical bubbles (below $1 \mathrm{~mm}$ ). This phenomenon does not exist with the capillary as, contrary to the membrane punctured over its entire surface sheet, this sparger is located tangentially to the wall at the column base and generates only one train of large bubbles (spherical cap shape, above $10 \mathrm{~mm}$ ) rising along the column wall according to trajectories which follow the main streamlines induced by the swirling motion.

Figure 10 also shows the influence of the Velocity Factor on the volumetric mass transfer coefficients. For the membrane, the swirling motion has a negative impact: when compared to $V F 1, k_{L} a$ is reduced by a factor varying between 1.1 and 1.3 for $V F 4$, and between 1.6 to 1.2 for VF9. In contrast, for the capillary sparger, the greatest coefficients are obtained for VF4, whereas VF1 and VF9 lead to similar values. These tendencies remain difficult to analyze without quantitative measurements for bubble sizes and gas retentions. Nevertheless, the hypothesis that can be put forward concerns the mechanisms of bubble formation at the sparger which are: (i) fundamentally different depending on the air sparger type (one train of large bubbles against an air column bursting into small bubbles), and (ii) susceptible to be 
disturbed according to the nature and the intensity of the liquid motion produced at the exit of the connection flange.

For superficial gas velocities varying from 0.004 to $0.010 \mathrm{~m} . \mathrm{s}^{-1}$, Table 3 reports the ratio of the volumetric mass transfer coefficients measured, either in the Conway medium (CM) or in seawater (SW), to the ones in tap water (TW). For the capillary sparger (T), these ratios are almost constant and close to 1 whatever the Velocity Factors: the physico-chemical properties of sea media do not therefore modify the aeration performances of this sparger, probably due to the large sizes of the bubbles produced. This is not the case with the membrane sparger where $k_{L} a$ are two to four times higher in presence of seawater and Conway medium, this phenomenon being more pronounced when VF increases. These tendencies should also here come from the bubble formation mechanisms.

Lastly, whatever the operating conditions, the volumetric gas-liquid mass transfer coefficients vary between $0.001 \mathrm{~s}^{-1}$ and $0.013 \mathrm{~s}^{-1}$ in Conway medium. For design purposes, it is now interesting to qualitatively compare these aeration performances with the oxygen produced photosynthetically by the microalga Isochrysis affinis galbana. The single-module photobioreactor was not equipped to follow either the dissolved oxygen concentration or the gas composition during the microalgal cultures. Consequently, a Chlorolab2 ${ }^{\circledR}$ system (Hansatech Instruments ${ }^{\circledR}$ ) has been used to estimate, under controlled conditions of temperature and irradiance, both respiration and photosynthesis (liquid phase measurements). It reveals that the oxygen production by Isochrysis affinis galbana is almost $6.10^{-10}$ $\mu \mathrm{molO} 2 \cdot$ cell $^{-1} \cdot \mathrm{min}^{-1}$ at an irradiance of $250 \mu \mathrm{mol} \cdot \mathrm{m}^{-2} \cdot \mathrm{s}^{-1}$. The continuous cultures run in the single-module photobioreactor have lead to a cellular concentration of $4.26 .10^{10}$ cell.L ${ }^{-1}$ at equilibrium for this incident light flux (Figure11). Using this value, an oxygen production of $25.5 \mu \mathrm{mol} . \mathrm{L}^{-1} \cdot \mathrm{min}^{-1}$ is deduced. If, by a very simple approach, this production is directly extrapolated to the total liquid volume of the single-module photobioreactor $\left(V_{L}=6.1 \mathrm{~L}\right)$, a 
flow rate of oxygen produced equal to $0.083 \mathrm{mg} . \mathrm{s}^{-1}$ is obtained. In parallel, the oxygen physically transferable from liquid to gas phases (namely by desorption) is expressed by:

$N_{O_{2}}=k_{L} a \cdot V_{L}\left(C_{P}-C_{L}^{*}\right)$

where $C_{L}^{*}$ is here equal to $6.9 \mathrm{mg} \cdot \mathrm{L}^{-1}$ (Conway medium, $25^{\circ} \mathrm{C}, \mathrm{P}_{\mathrm{atm}}$ ). By substituting 0.083 mg. $\mathrm{s}^{-1}$ into Eq. (17) and by considering the worst and the best aeration performances $\left(k_{L} a=\right.$ 0.001 and $0.013 \mathrm{~s}^{-1}$ respectively), the exchange potentials, $\Delta C=C_{P}-C_{L}^{*}$, necessary to remove all the oxygen produced are then ranging from 13 to $1 \mathrm{mg} . \mathrm{L}^{-1}$. In view of these low values, it is reasonable to conclude that the single-module photobioreactor will be able to evacuate the oxygen produced. Consequently, for such geometrical configuration of photobioreactor, the microalgal growth will not be a priori limited by gas-liquid mass transfer, whatever the operating conditions that could be retained in the end. Nevertheless, to definitively conclude on this point, more advanced investigations have to be conducted, based, in particular, on oxygen in-situ measurements (both liquid and gas phases) during cultures.

\section{Continuous microalgal cultures}

Isochrysis affinis galbana continuous cultures are compared depending on whether an axial (VF1) or a swirling flow (VF4) is generated inside the single-module photobioreactor, the other experimental conditions being similar (see Material and Methods above). Typical growth curves are plotted in Figure 11 for both Velocity Factors. The nature of the flow induced inside the photobioreactor has no effect on the cellular concentration at equilibrium: in both cases, after almost 15 days, the cultures reach an equilibrium corresponding to 4.3.10 $0^{10} \pm 0.2 .10^{10}$ cell. $L^{-1}$ which is maintained until the cultures are stopped on day 40 . The experimental volumetric productivities are calculated at the equilibrium: no significant difference is detected between both FV1 and FV4, leading to an average productivity of 1.64.10 $10 \pm 3.10^{8}$ cell. $\mathrm{L}^{-1} \cdot \mathrm{d}^{-1}$. This result is consistent as the productivity inside phobioreactors is only controlled by the reactor geometry (defining the illuminated specific surface) and by 
the light input, and independently of hydrodynamics (Pruvost et al 2008). One exception appears when the microalgae are sensitive to light/dark cycle effects: a dynamic coupling occurs then between biological response and fluctuating light regimes encountered by flowing cells, thus implying an alteration of the photosynthetic conversion and a modification of the photobioreactor efficiency (Janssen et al 2000, Richmond 2004). Here, this phenomenon does not a priori exist due to the small incident flux applied.

For identical conditions $\left(q_{0}=250 \mu \mathrm{mol} . \mathrm{m}^{-2} \cdot \mathrm{s}^{-1}, D=0.36 \mathrm{~d}^{-1}\right)$, the theoretical productivity was close to 3.0.10 ${ }^{10}$ cell. $\mathrm{L}^{-1} \cdot \mathrm{d}^{-1}$ (Figure 6b), and thus is rather in agreement with the experimental one. The difference can be explained by: (i) experimental uncertainties (cell counting, fluctuating dilution rate), (ii) the assumptions associated with light transfer modelling (collimated incident flux, optical properties and cellular mass of Isochrysis affinis galbana).

It is now interesting to compare these results with larval needs in hatcheries which, as aforementioned, are averaged to $1 \cdot 2 \cdot 10^{12}$ cell. $\mathrm{d}^{-1}$. By considering $P_{X}=1.64 .10^{10}$ cell. $\mathrm{L}^{-1} . \mathrm{d}^{-1}$,

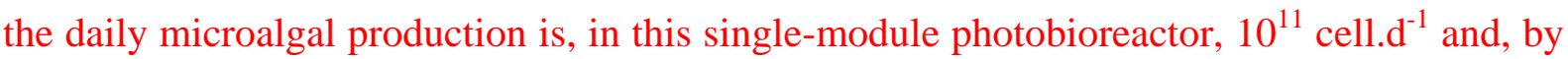
extrapolating to a 120 -L multimodule one, $2.10^{12}$ cell. $\mathrm{d}^{-1}$. Such latter volume would enable the averaged larval requirements to be covered. Note that the multimodule photobioreactor should be designed so as to adjust its microalgal production to the hatchery size, by modifying either the number of modules (i.e. the culture volume) or, the light flux (see Figure 6b). For the highest productions, another alternative is to use several identical multimodule photobioreactors in parallel.

Finally, Figure 12 presents some photographs illustrating fouling deposition at internal walls after 40 days of continuous cultures, submitted to an axial (VF1) or a swirling flow (VF4). It clearly demonstrates that the microalgal deposition is significantly lower when a swirling motion is generated. Even if no fine analysis has been performed here to understand how local hydrodynamics affects biofouling, it is reasonable to suppose that this result is closely related 
to hydrodynamic characteristics inherent to swirling flows, namely: a high turbulence intensity, great tangential components of velocity close to walls (Figure 8) and high levels of wall friction (Gupta et al 1984, Legentilhomme and Legrand 1991, Pruvost et al 2000). This ability of swirling flows to limit the biofilm formation is particularly interesting for long-term continuous cultures because it suggests that the reactor walls could be maintained almost transparent. This will be helpful to prevent the irradiance received by microalgae from decreasing as long as the biofilm is depositing at walls. This phenomenon should not be neglected as it can induce a long-term reduction in productivity.

To conclude, the continuous cultures run in the single-module photobioreactor have shown that (i) the volumetric productivity is equal to $1.64 .10^{10} \pm 3.10^{8}$ cell. $\mathrm{L}^{-1} \cdot \mathrm{d}^{-1}$ and remains constant whatever the hydrodynamic conditions $\left(q_{0}=250 \mu \mathrm{mol} \cdot \mathrm{m}^{-2} \cdot \mathrm{s}^{-1}, D=0.36 \mathrm{~d}^{-1}\right)$, (ii) the microalgal production required in hatcheries can be satisfied, (iii) the microalgal deposition at walls is reduced when a swirling flow is generated instead of an axial one. In the specific context of hatcheries, these three points offer undeniable advantages as the continuous microalgal cultures have to be run during several months with a productivity that should remain constant for optimizing larvae feeding.

\section{CONCLUSIONS}

The present work has reported investigations carried out to optimize both design elements and dimensions of a new photobioreactor for continuous production in mollusk hatcheries. The design has preliminarily been turned into an external-loop airlift configuration based on a succession of elementary modules, each one being composed of two transparent vertical interconnected columns. The liquid circulation is ensured pneumatically with respect to a swirling motion (tangential inlets). A single module of the whole photobioreactor was built up. Firstly, the two-flux radiative transfer model was adapted to account for refraction effects 
(front surface curvature) and for the optical properties of Isochrysis affinis galbana. The growth curve of this microalga was determined by using a planar torus photobioreactor and modeled with respect to a Monod law. By coupling the previous light and growth models, the volumetric productivities were predicted as a function of incident light flux, dilution rate and column radius. These results have revealed that a column radius of $0.03 \mathrm{~m}$ represents a good compromise between productivity and building cost price; therefore, this radius will be retained for scaling the multimodule photobioreactor. In a second step, the hydrodynamics of the liquid phase was modeled in terms of global flow behavior (mean circulation velocity, Péclet number) and of swirling motion decay. The generation of a swirling flow motion was logically proven positive for enhancing mixing. Whatever the operating conditions, the swirling motion, characterized by high tangential components of velocity, was conserved but significantly attenuated along the column. Thus, it is reasonable not to exceed a column height of $1 \mathrm{~m}$ for the multimodule system. In a third time, the aeration performances were determined by overall volumetric mass transfer coefficient measurements and demonstrated that the single-module photobioreactor had the physical capacity to remove the oxygen produced photosynthetically. Finally, Isochrysis affinis galbana continuous cultures were run for geometrical configurations generating either an axial or a swirling motion (the other conditions remaining similar: $q_{0}=250 \mu \mathrm{mol} \cdot \mathrm{m}^{-2} \cdot \mathrm{s}^{-1}, D=0.36 \mathrm{~d}^{-1}$ ). In both cases, the same productivity was reached: $1.64 .10^{10} \pm 3.10^{8}$ cell. $\mathrm{L}^{-1} \cdot \mathrm{d}^{-1}$. When accounting for experimental sensitivity and light modelling assumptions, this value was found to agree with the predicted data. Although no influence of hydrodynamics existed on productivity, some differences appeared in terms of biofouling. Indeed, the film deposited at walls was significantly thinner when a swirling motion was generated. To maintain high biological performances for longterm continuous cultures, such result is of great importance.

Coupled with technico-economical considerations, these investigations led us to design and 
build up a 120-L prototype made of 18 elementary modules $(0.06 \mathrm{~m}$ in diameter, $1 \mathrm{~m}$ in length) connected by flanges equipped with VF4 prisms. As illustrated in Figure 13, the fluorescent lamps are inserted between columns and uniformly spaced. The column assembly was optimized to restrict floor-space $(1 \mathrm{~m} \times 1.1 \mathrm{~m} \times 1.65 \mathrm{~m})$. Air injections were regularly dispatched in the prototype and performed by using capillaries placed tangentially to walls at the column base. The prototype can pivot according to a horizontal axis, thereby making cleaning and sterilization steps easier and less manpower intensive. Isochrysis affinis galbana continuous cultures were successfully run in this prototype (results not exposed here) and led to a microalgal production of stable quality and quantity under controlled conditions.

The comparison in terms of volumetric productivity with other commercialized systems is difficult to set up as the complete set of parameters (i.e. microalga type, incident light flux, dilution rate) is not most often available. The first one is the CAPS systems from the Sea Salter Shellfish ${ }^{\circledR}$ Company. They are bags or sleeve polyethylene reactors, suspended from a framework or supported within a mesh frame, indoors or outdoors, in which the culture is mixed by bubbling air. Under artificial illumination (the irradiance and the microalga type being non precised unknown), the 500-L CAPS systems would yield 80-120 L of microalgae per day with a cell density of $4.10^{9}$ cell.L - $^{-1}$ (http://www.seacaps.com/specs.htm); the associated volumetric productivities would thus be ranging from $6.4 \cdot 10^{8}$ to $9.6 \cdot 10^{8}$ cell. $\mathrm{L}^{-1} \cdot \mathrm{d}^{-1}$. The second competing system is the Biofence ${ }^{\circledR}$ photobioreactor (Cell Pharm ${ }^{\circledR}$ company) which is based on tubular units consisting of a vertical array of horizontal tubes connected to manifolds in a fence-like configuration. About $1 / 3^{\text {rd }}$ of the total system volume of algae per day would be harvested per block (each block being composed of 16 tubes, namely $100 \mathrm{~L}$ in volume) and a concentration of $20.10^{9}$ cells of Isochrysis galbana per Liter would be reached for indoor cultures (unknown irradiance, http://www.variconaqua.com/new_page_2.htm); the associated volumetric productivities would thus be equal to $6 \cdot 6 \cdot 10^{9}$ cell. $\mathrm{L}^{-1} \cdot \mathrm{d}^{-1}$. Both CAPS 
and Biofence ${ }^{\circledR}$ systems lead therefore to volumetric productivities smaller than in the multimodule photobioreactor $\left(1.64 .10^{10}\right.$ cell. $\left.\mathrm{L}^{-1} \cdot \mathrm{d}^{-1}\right)$. In addition, the designed system offers other undeniable advantages for optimizing the mollusk larvae feeding: (i) it is expandable in elementary modules (i.e. adjustable to the microalgal production required), (ii) it is based on a pneumatic agitation (lower power input and more respectful for cell integrity), (iii) the fouling at walls is minimized, (iv) it is less manpower intensive (ability to ensure long-term continuous cultures, easy to clean and sterilize) and restricted in floor-space. Currently, this prototype has been implemented in a French mollusk hatchery (Vendée Naissain ${ }^{\circledR}$ ) and will be commercialized by the company Jouin Solutions Plastiques®.

\section{ACKNOWLEDGMENTS}

The development of this work was made possible by the technical and financial support (CIFRE fellowship) of the plastic company Jouin Solutions Plastiques ${ }^{\circledR}$ (www.jouin.com); the authors are especially grateful for helpful discussions and suggestions provided by JeanClaude Jouin. The authors would like to acknowledge also the French Region Pays-de-laLoire for partly supporting this work through SMIDAP research program. Thanks to Loic Le Déan (Ifremer Nantes) for his technical help.

\section{NOMENCALTURE}

$b \quad$ backward scattering coefficient

C tracer concentration inside the reactor

$C_{L} \quad$ dissolved oxygen concentration inside the liquid phase

$C_{L}^{*} \quad$ dissolved oxygen concentration at saturation inside the liquid phase

$C_{P} \quad$ dissolved oxygen concentration inside the probe

$C_{\propto}$ final tracer concentration inside the reactor [dimensionless]

$$
\begin{aligned}
& {\left[\mathrm{mol} . \mathrm{m}^{-3}\right]} \\
& {\left[\mathrm{mol} . \mathrm{m}^{-3}\right]} \\
& {\left[\mathrm{mol} . \mathrm{m}^{-3}\right]} \\
& {\left[\mathrm{mol} . \mathrm{m}^{-3}\right]} \\
& {\left[\mathrm{mol} . \mathrm{m}^{-3}\right]}
\end{aligned}
$$


$D$ dilution rate

$D_{a x}$ axial dispersion coefficient

$E_{a}$ mass absorption coefficient $\left[\mathrm{m}^{2} \cdot \mathrm{kg}^{-1}\right]$

$E_{s} \quad$ mass scattering coefficient $\left[\mathrm{m}^{2} \cdot \mathrm{kg}^{-1}\right]$

G spherical irradiance $\left[\mu \mathrm{mol} . \mathrm{m}^{-2} \cdot \mathrm{s}^{-1}\right]$

$G_{C}$ compensation irradiance $\left[\mu \mathrm{mol} \cdot \mathrm{m}^{-2} \cdot \mathrm{s}^{-1}\right]$

$I^{+}$specific radiant intensity relative to the incident light flux direction $\left[\mu \mathrm{mol} . \mathrm{m}^{-2} \cdot \mathrm{s}^{-1}\right]$

$I^{-}$specific radiant intensity relative to the opposite direction of incident light flux (backward scattering part)

$$
\begin{array}{r}
{\left[\mu \mathrm{mol} . \mathrm{m}^{-2} \cdot \mathrm{s}^{-1}\right]} \\
{\left[\mu \mathrm{mol} . \mathrm{m}^{-2} \cdot \mathrm{s}^{-1}\right]} \\
{\left[\mathrm{s}^{-1}\right]} \\
{[\mathrm{m}]} \\
{[\mathrm{m}]}
\end{array}
$$

$K_{G} \quad$ limitation constant

$k_{L} a$ overall volumetric mass transfer coefficient

L light path length

$L_{t} \quad$ mean reactor length $\left(L_{t}=2.32 \mathrm{~m}\right)$

$P e_{L} \quad$ Péclet number based on the mean reactor length $\left(P e_{L}=\frac{U_{C} \cdot L_{t}}{D_{a x}}\right)$

[dimensionless]

$P_{X} \quad$ volumetric microalgal productivity

$$
\left[\text { cell. } \mathrm{m}^{-3} \cdot \mathrm{s}^{-1}\right]
$$

$q_{O}$ averaged incident radiant light flux on the reactor surface

$$
\left[\mu \mathrm{mol} . \mathrm{m}^{-2} \cdot \mathrm{s}^{-1}\right]
$$

$r \quad$ radial coordinate inside the column

$R \quad$ radius of the single-module photobioreactor column

Sn swirl number

$t$ time

$t_{C} \quad$ mean circulation time

$t_{m} \quad$ mixing time defined using a homogeneity degree equal to 95\%

$t_{p} \quad$ time constant of the oxygen probe

$U$ axial component of time-averaged velocity 
$U_{C}$ mean circulation velocity

$$
\left[\mathrm{m} . \mathrm{s}^{-1}\right]
$$

$U_{G} \quad$ superficial gas velocity defined with respect to the column section

$\left[\mathrm{m}^{2} \cdot \mathrm{s}^{-1}\right]$

$V_{L} \quad$ total liquid volume inside the single-module photobioreactor

$\left[\mathrm{m}^{3}\right]$

VF Velocity Factor

[dimensionless]

W tangential component of time-averaged velocity

$\left[\mathrm{m} . \mathrm{s}^{-1}\right]$

$x \quad$ axial coordinate inside the downcomer column, the origin being at the top

[m]

X cellular concentration

[cell. $\mathrm{m}^{-3}$ ]

Z position along the culture depth

[m]

$z^{*} \quad$ geometrical distance between tracer injection and detection points

[dimensionless]

\section{Greek letters}

$\alpha \quad$ linear scattering modulus

[dimensionless]

$\delta \quad$ two-flux extinction coefficient

$\left[\mathrm{m}^{-1}\right]$

$\varepsilon_{G} \quad$ mean gas hold-up inside the pilot

[dimensionless]

$\mu \quad$ specific growth rate

$\mu_{m} \quad$ maintenance term linked to respiration

$\mu_{\max }$ maximal specific growth rate

$\theta$ ratio between time and mean circulation time

[dimensionless]

$\theta_{C} \quad$ angular position inside the column

[radian]

\section{REFERENCES}

Aoubed H, Legentilhomme P, Nouar C, Legrand J 1994. Experimental comparison of electrochemical and dot-paint methods for the study of swirling flow. J. Appl. Electrochem. 24:619-625.

Benkhelifa H, Legrand J, Legentilhomme P, Montillet A 2000. Study of the hydrodynamic behavior of the batch and continuous torus reactor in laminar and turbulent flow regimes 
by means of tracer methods. Chem. Eng. Sci. 55:187-1882

Borowitzka MA 1997. Microalgae for aquaculture: Opportunities and constraints. J. Appl. Phycol. 9:393-401.

Carvalho AP, Meireles LA, Malcata FX 2006. Microalgal reactors: A review of enclosed system designs and performances, Biotechnol. Prog. 22:1490-1506

Chisti YM 1989. Airlift Bioreactors. London, England, Elsevier Applied Science.

Cornet J-F, Dussap C-G, Gros J-B 1995. A simplified monodimensional approach for modeling coupling between radiant light transfer and growth kinetics in photobioreactors. Chem. Eng. Sci. 50(9):1489-1500

Coulteau P, Sorgeloos P 1992. The use of algal substitutes and the requirement for live algae in hatchery and nursery rearing of bivalve mollusks: an international survey. Journal of Shellfish Research 11:467-476.

Falkowski PG, Dubinsky Z, Wyman K 1985. Growth-irradiance relationships in phytoplankton. Limnology and Oceanography 30(2):311-321.

Green JC, Leadbeater BSC 1994. The Haptophyte algae. Oxford, England, The Systematics Association special volume ISBN 0-198-57772-9 446.

Gupta A, Lilley DG, Syred N 1984. Swirl flow. Energy and engineering sciences series. Abacus Press Cambridge.

Hébrard G, Bastoul D, Roustan M 1996. Influence of the gas sparger on the hydrodynamic behavior of bubble columns. Trans. IChem. E. 74(A):406-414.

Ingham J, Dunn IJ, Heinzle E, Prenosil JE 1994. Chemical Engineering Dynamics, Modeling with PC simulation. New York, USA, VCH publishers Inc. ISBN 3-527-28577-6. pp. 127. Janssen M, Janssen M, de Winter M, Tramper J, Mur LR, Wijffels RH 2000. Efficiency of light utilization of Chlamydomonas reinhardtii under medium-duration light/dark cycles. J. Biotechnology 78:123-137 
Loubière K, Hébrard G, Guiraud P 2003. Dynamics of bubble growth and detachment from rigid and flexible orifices. Can. J. Chem. Eng. 81(3-4): 499-507

Legentilhomme P, Legrand J 1991. The effects of inlet conditions on mass transfer in annular swirling decaying flow. Int. J. Heat Mass Transfer 34:1281-1291

Molina Grima E, García Camacho F, Sanchez Perez JA, Acién Fernández FG, Fernandez Sevilla JM 1997. Growth yield determination in a chemostat culture of the marine microalga Isochrysis galbana. J. Applied Ecology 8:529-534.

Muller-Feuga A, Le Guedes R, Pruvost J 2003a. Benefits and limitations of modeling for optimization of Porphyridium cruentum cultures in an annular photobioreactor. J. Biotech. 102(2):153-163

Muller-Feuga A, Pruvost J, Le Guedes R, Le Dean L, Legentilhomme P, Legrand J 2003b. Swirling flow implementation in a photobioreactor for batch and continuous cultures of Porphyridium cruentum. Biotech. Bioeng. 84(5):544-551

Pottier L, Pruvost J, Deremetz J, Cornet J-F, Legrand J, Dussap CG 2005. A fully predictive model for one-dimensional light attenuation by Chlamydomonas reinhardtii in a torus photobioreactor. Biotech. Bioeng. 91(5):569-582.

Pruvost J, Legrand J, Legentilhomme P 2000. Particle image velocimetry investigation of the flow-field of a 3D turbulent annular swirling decaying flow induced by means of a tangential inlet. Exp. in Fluids 29:291-301

Pruvost J, Legrand J, Legentilhomme P, Muller-Feuga A 2002. Simulation of microalgae growth in limiting light conditions. AIChE J. 48(5):110-1120.

Pruvost J, Pottier L, Legrand J 2006. Numerical investigation of hydrodynamic and mixing conditions in a torus photobioreactor. Chem. Eng. Sci. 61(14):4476-4489.

Pruvost J, Cornet J-F, Legrand J 2008. Hydrodynamics influence on light conversion in photobioreactors: an energetically consistent analysis. Chem. Eng. Sci. 
doi:10.1016/j.ces.2008.04.026

Richmond A 2004. Handbook of microalgal mass culture: biotechnology and applied phycology. Blackwell Science Ltd

Rico-Villa B, Le Coz JR, Mingant C, Robert R 2006. Influence of phytoplankton diet mixtures on microalgae consumption, larval development and settlement of the Pacific oyster Crassostrea gigas (Thunberg). Aquaculture 256(1-4):377-388.

Roustan M 2003, Transferts gaz-liquide dans les procédés de traitement des eaux et des effluents gazeux, Editions Dec \& Doc, Paris

Sanchez Miron A, Garcia Camacho F, Contreras Gomez A, Molina Grima E, Chisti Y 2000. Bubble Column and Airlift photobioreactors for algal culture. AIChE 46(9):1872-1887

Spolaore P, Joannis-Cassan C, Duran E, Isambert A 2006. Review: Commercial applications of microalgae, Journal of Bioscience and Bioengineering 101(2):87-96

Sukenik A, Wahnon R 1991. Biochemical quality of marine unicellular algae with special emphasis on lipid composition. I. Isochrysis galbana. Aquaculture 97(1):61-72

Tzovenis I, De Pauw N, Sorgeloos P 2003. Optimization of T-iso biomass production rich in essential fatty acids I. Effect of different light regimes on growth and biomass production. Aquaculture 216(1-4):203-222.

Vandu CO, Koop K, Krishna R 2004. Volumetric mass transfer coefficient in a slurry bubble column operating in the heterogeneous flow regime. Chem. Eng. Sci. 59:5417-5423

Wu WT, Wu JY, Jong JZ 1992. Mass transfer in an airlift reactor with a net draft tube. Biotechnol. Prog. 8(5):465-468

TABLE LEGEND

Table 1. Composition of the Conway medium. The mass reported (in grams) is defined per 
Liter of distilled water, the medium being prepared with $1 \mathrm{~mL}$ of each solution per Liter of seawater.

Table 2. Data issued from the global flow modeling $\left(2.2<U_{G}<9.4 \mathrm{~mm} . \mathrm{s}^{-1}\right)$

Table 3. Data issued from gas-liquid mass transfer measurements $\left(4<U_{G}<10 \mathrm{~mm} . \mathrm{s}^{-1}\right)$ :

\section{FIGURE LEGEND}

Figure 1. (a) Schematic representation of the single-module photobioreactor: [1] riser column, [2] downcomer column, [3] lower connection flange, [4] upper connection flange, [5] membrane sparger, [6] capillary sparger. (b) Photograph showing the body of a connection flange and the prism-shaped inserts defining the Velocity Factors FV2, FV4 and FV9 (left to right). (c) Schematic representation of a connection flange (swirling motion generation).

Figure 2. Top view (a) and Front view (b) of the PIV set-up: [1] flanges, [2] riser column, [3] downcomer column, [4] CCD Camera, [5] laser beam generator, [6] laser sheet, [7] air sparger

Figure 3. Attenuation profiles of irradiances $G(z) / q_{O}$ along the culture depth $z / L(L=60 \mathrm{~mm})$, for $q_{O}=210 \mu \mathrm{mol} . \mathrm{m}^{-2} \cdot \mathrm{s}^{-1}$ and $X=1.7 \cdot 10^{10}$ cell. $\mathrm{L}^{-1}$, without (solid line) and with (dashed line) taking optical distortion into account, the experimental irradiances being represented by blue circle symbols (o)

Figure 4. Irradiance fields over the column section for $q_{O}=210 \mu \mathrm{mol} . \mathrm{m}^{-2} \cdot \mathrm{s}^{-1}$ and $X=1.7 \cdot 10^{10}$ cell. $\mathrm{L}^{-1}$, without (left side) and with (right side) taking optical distortion into account

Figure 5. Specific growth rate $\mu$ of Isochrysis affinis galbana (clone Tahiti) versus irradiance $G$ received (solid line: model; symbol ‘ø’: experimental data) 
Figure 6. Predicted volumetric productivity: (a) as a function of dilution rate and column radius, for $q_{O}=250 \mu \mathrm{mol} \cdot \mathrm{m}^{-2} \cdot \mathrm{s}^{-1}$, (b) as a function of column radius for dilution rate $D=$ $0.36 \mathrm{~d}^{-1}$ and for several incident light flux: $q_{O}=100 \mu \mathrm{mol} . \mathrm{m}^{-2} . \mathrm{s}^{-1}$ (solid line), $200 \mu \mathrm{mol} . \mathrm{m}^{-}$ ${ }^{2} . \mathrm{s}^{-1}$ (dashed line) and $250 \mu \mathrm{mol} . \mathrm{m}^{-2} . \mathrm{s}^{-1}$ (dotted line)

Figure 7. Mean circulation velocity (a) and Péclet number based on the mean reactor length (b) versus superficial gas velocity for several Velocity Factors and air spargers (T: capillary placed tangentially to the column; M: membrane).

Figure 8. Radial profiles of axial- (top) and tangential- (bottom) components of velocity inside the downcomer column at different axial positions $x$ from the upper connection flange (membrane sparger; $Q_{G}=1.6 \mathrm{NL} \cdot \mathrm{min}^{-1}$ ): (a) VF4 (b) VF9

Figure 9. Swirl number as a function of axial position from the tangential inlet. The air flow rates (in NL. $\mathrm{min}^{-1}$ ) is put in brackets, $\mathrm{T}$ and $\mathrm{M}$ referring to air sparger type.

Figure 10. Volumetric gas-liquid mass transfer coefficient as a function of superficial gas velocity in the case of tap water

Figure 11. Typical growth curves of Isochrysis affinis galbana (cellular concentration versus time from inoculation), in cases where an axial flow (VF1) and a swirling flow (VF4) are generated inside the single-module photobioreactor $\left(q_{O}=250 \mu \mathrm{mol} . \mathrm{m}^{-2} \cdot \mathrm{s}^{-1}, D=0.36 \mathrm{~d}^{-1}\right.$, $Q_{G}=1.4 \mathrm{NL} \cdot \mathrm{min}^{-1}$, capillary sparger)

Figure 12. Photograph illustrating the biofouling deposited at walls after 40 days of Isochrysis affinis galbana continuous cultures, in the cases where an axial flow (VF1) and a swirling flow (VF4) are generated

Figure 13. Photographs of the 120-L multimodule photobioreactor (Top and front views) 
Figure 1

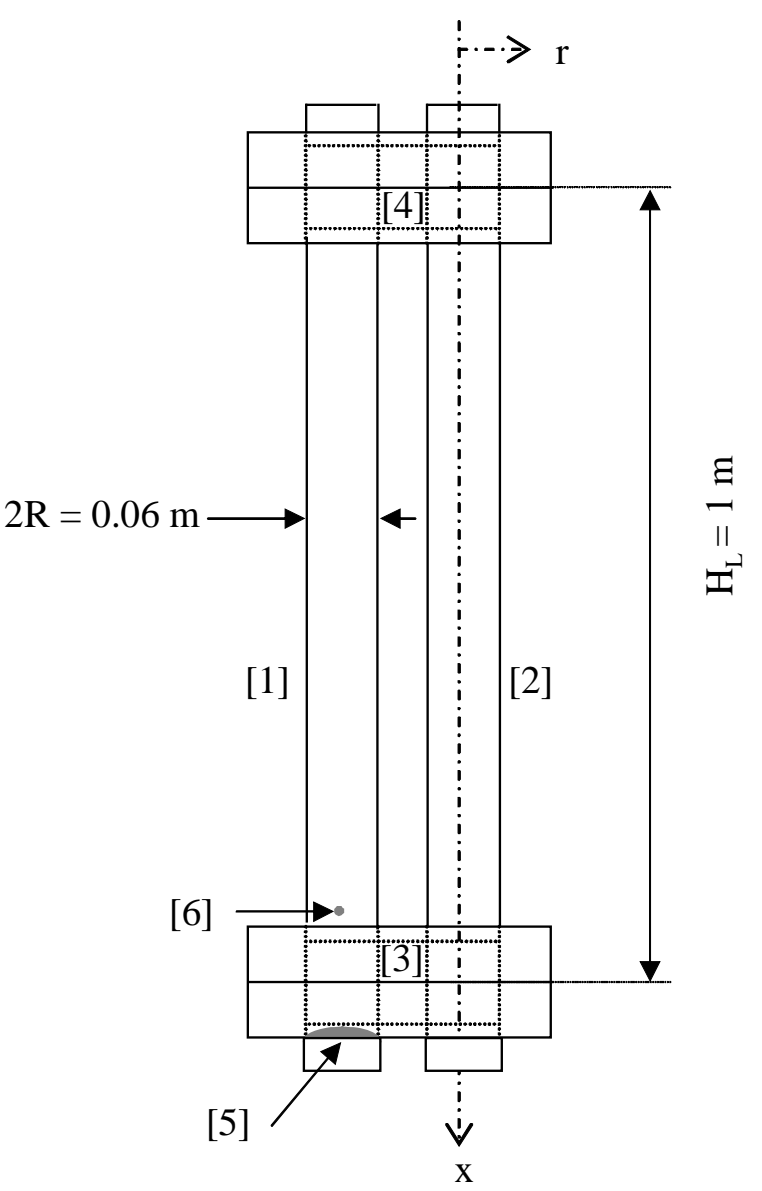

(a)

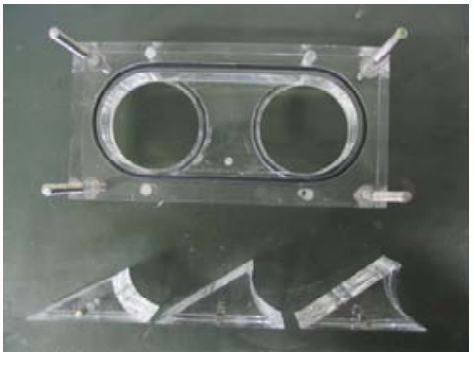

(b)

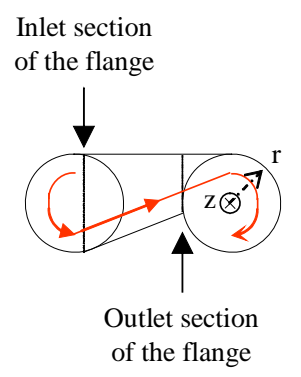

(c) 
Figure 2

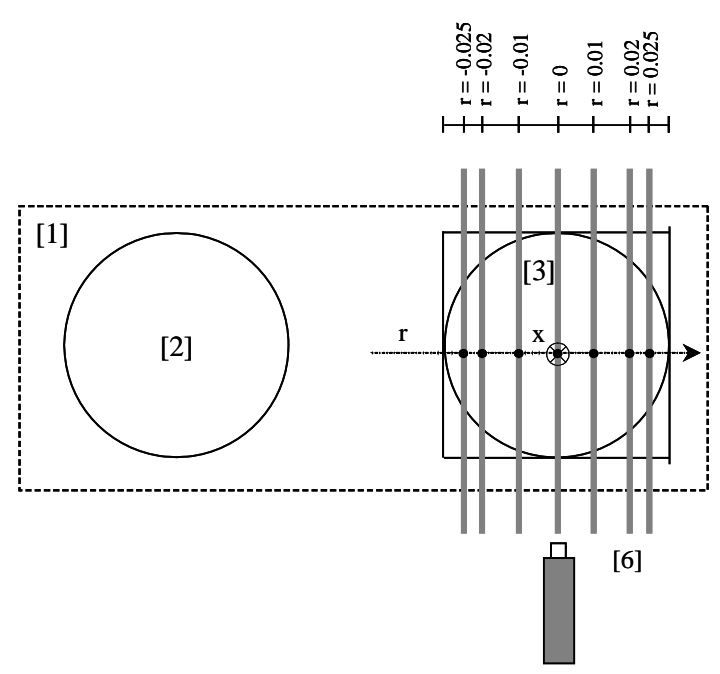

[5]

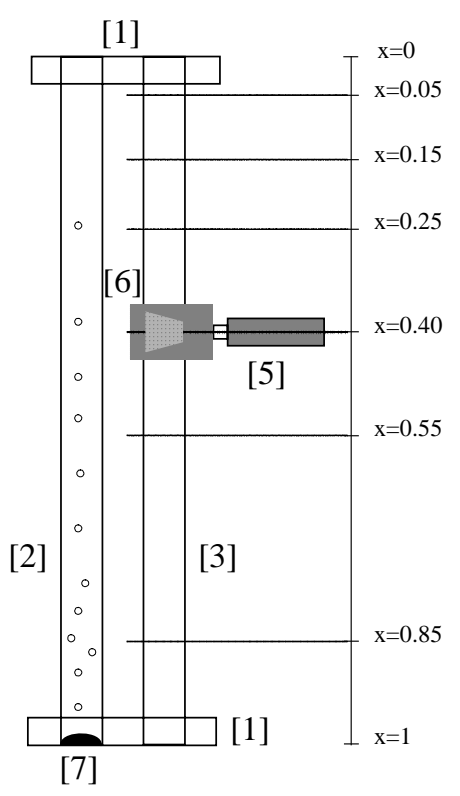

(b) 
Figure 3




Figure 4

Incident light flux
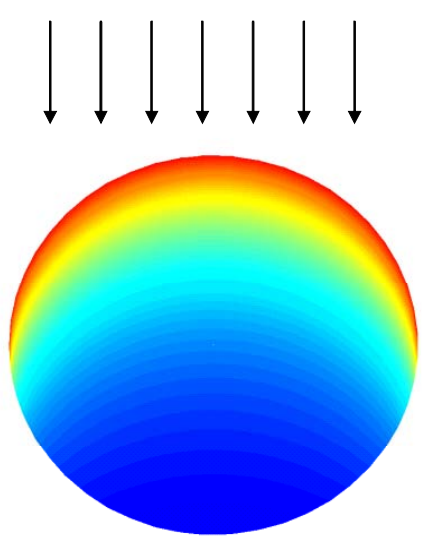

Incident light flux




Figure 5

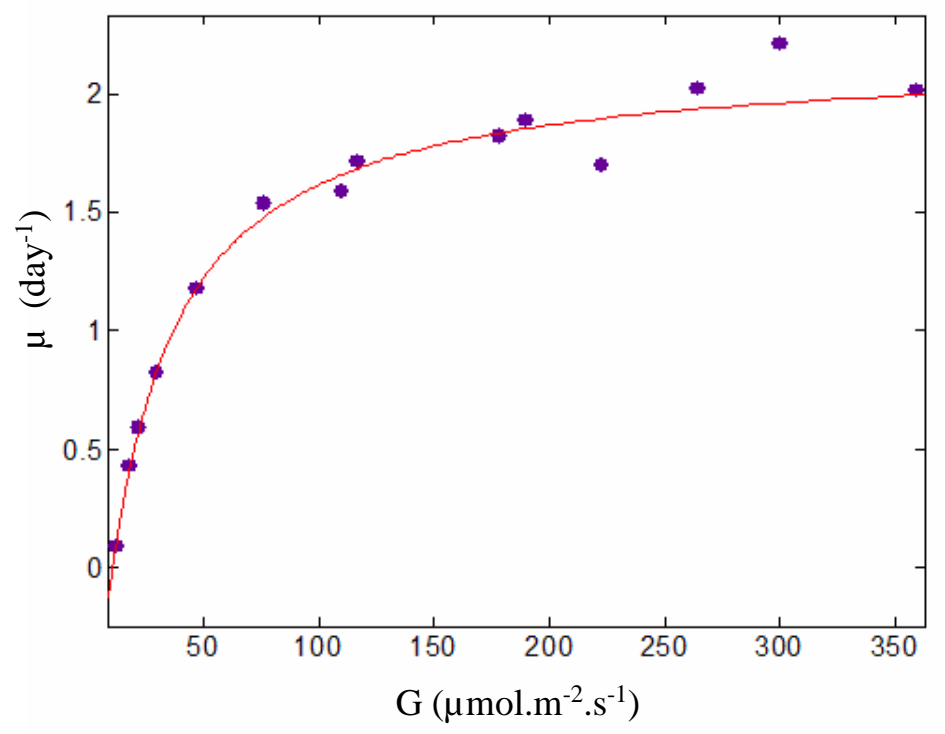


Figure 6

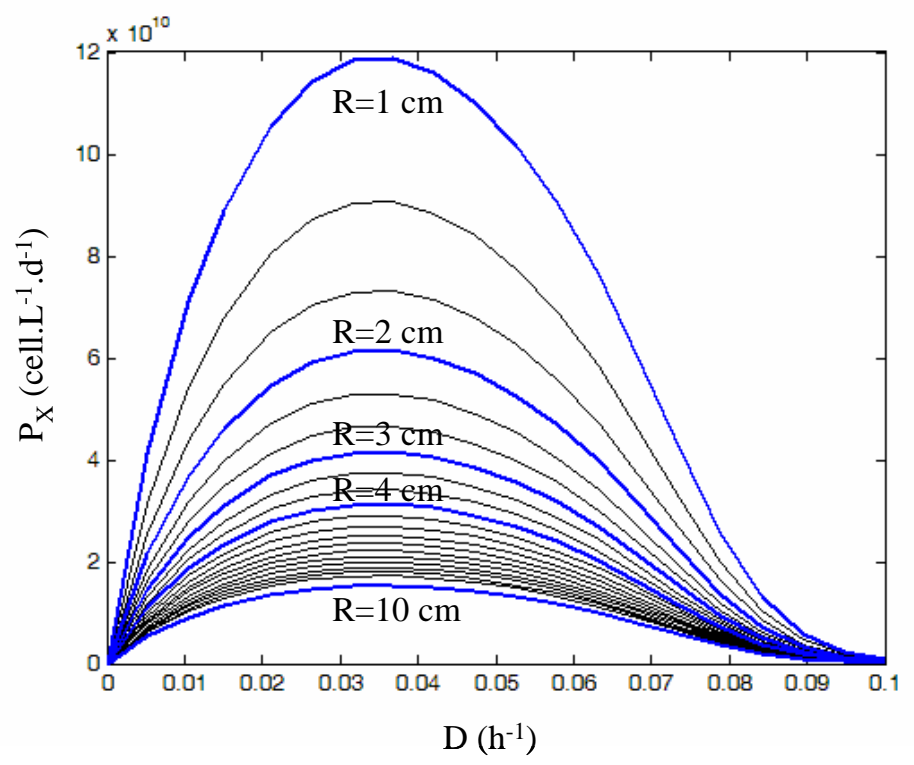

(a)

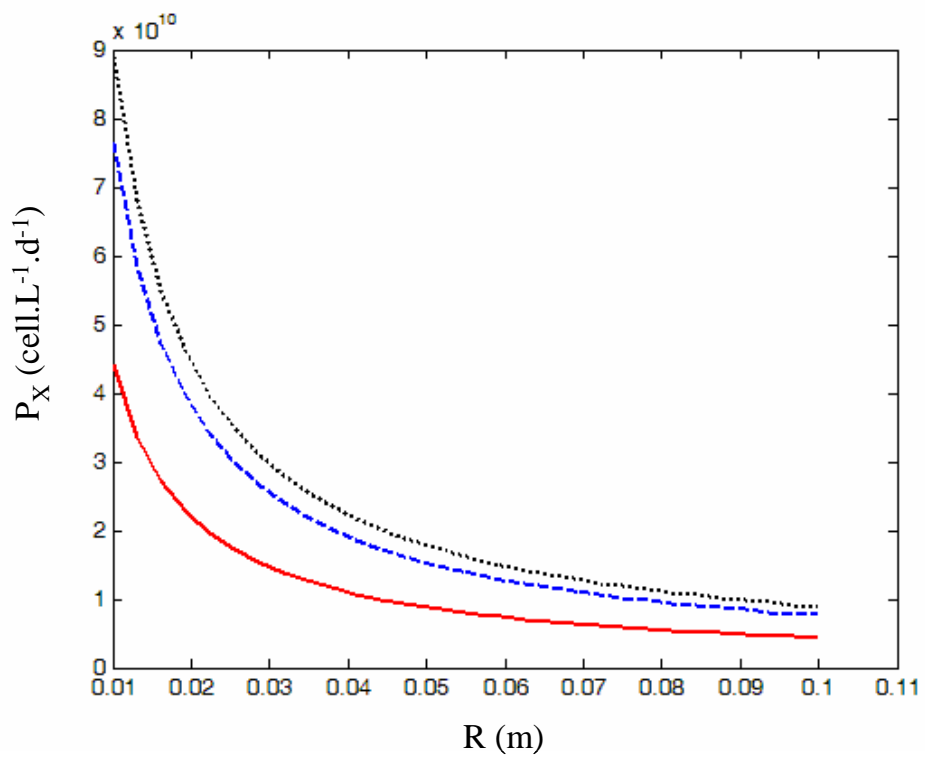

(b) 
Figure 7

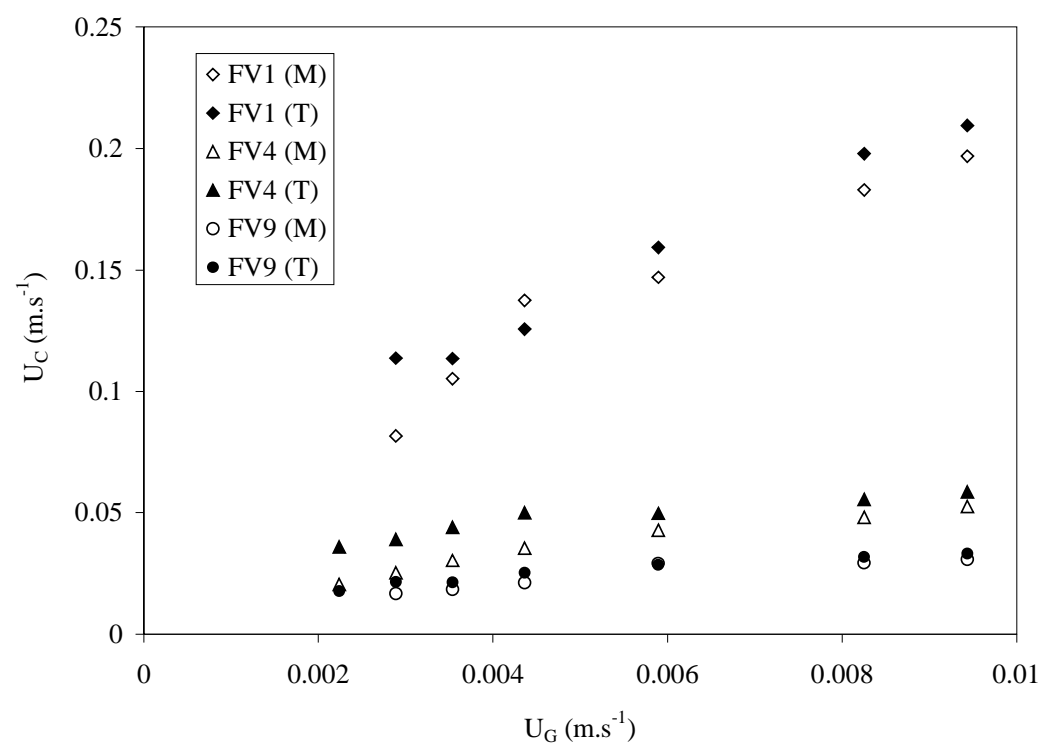

(a)



(b) 
Figure 8
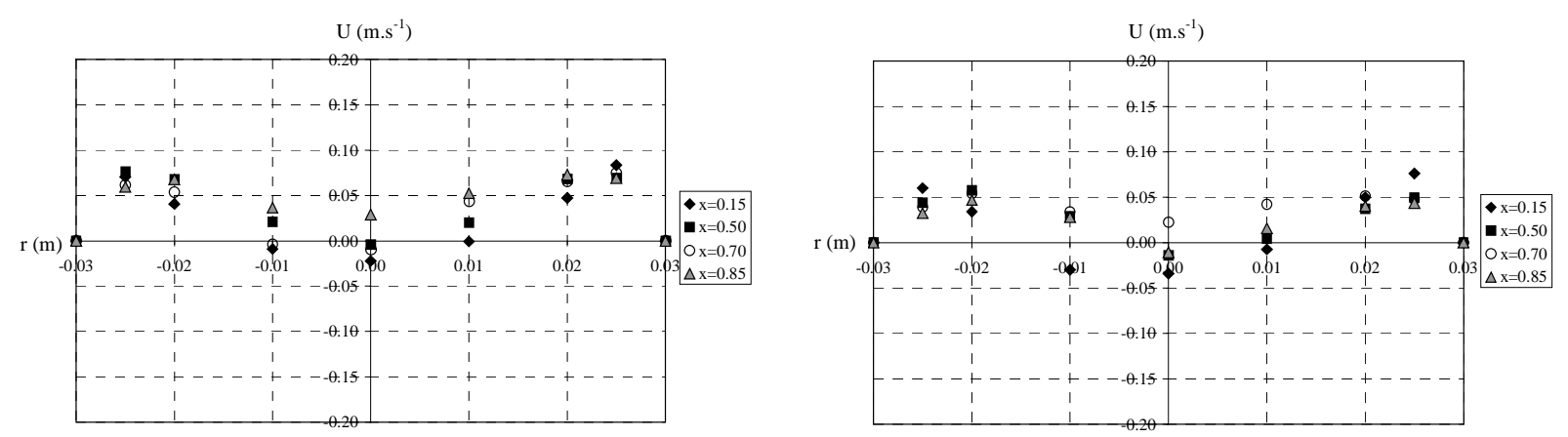

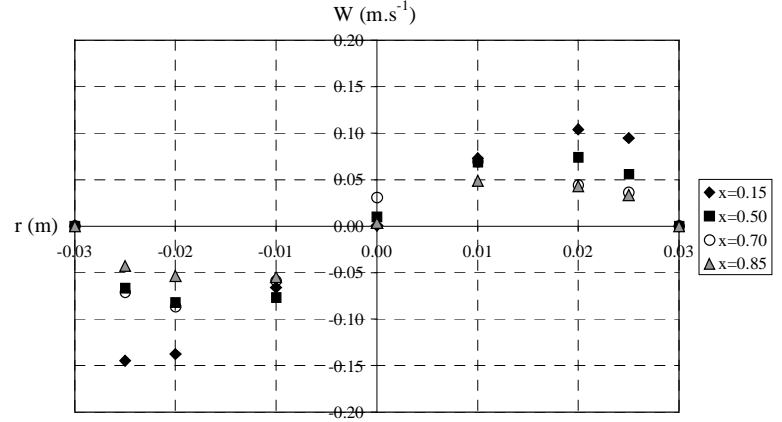

(a)



(b) 
Figure 9

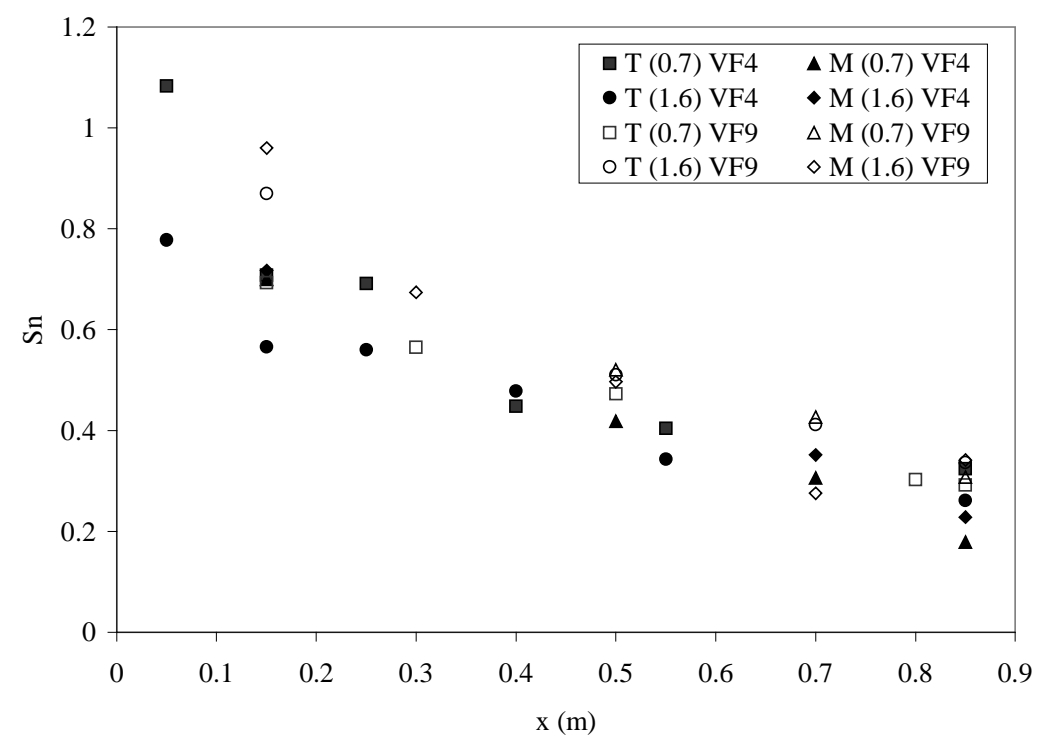


Figure 10

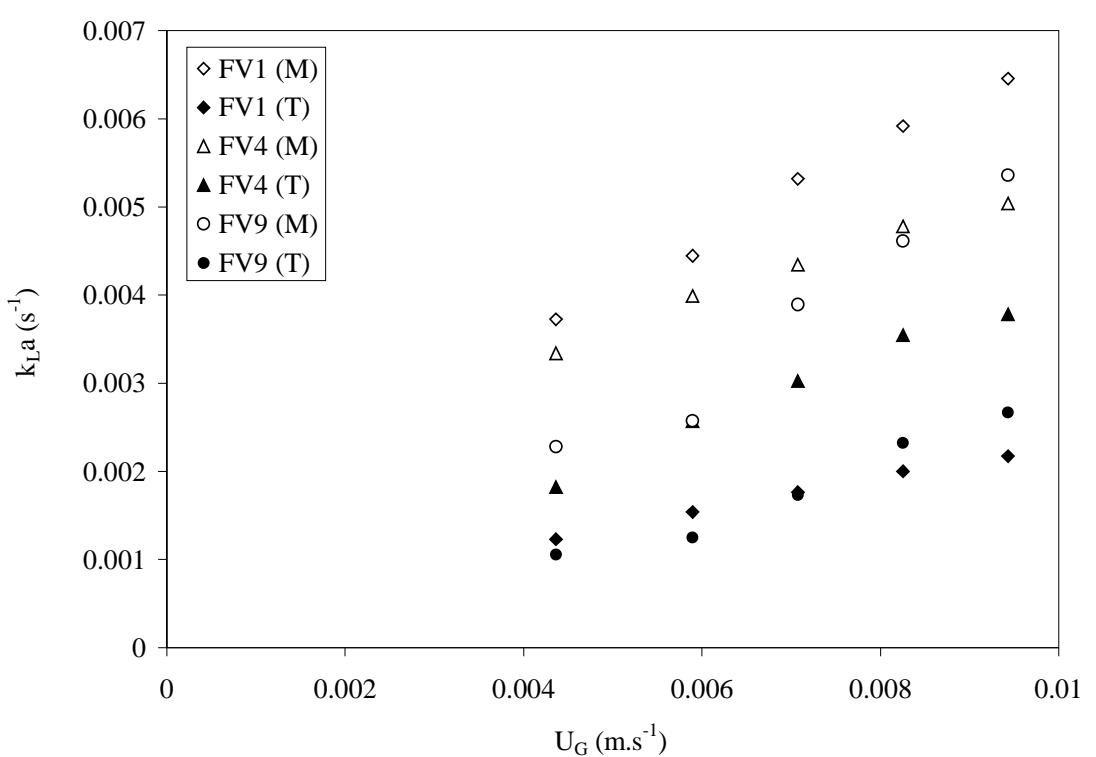


Figure 11

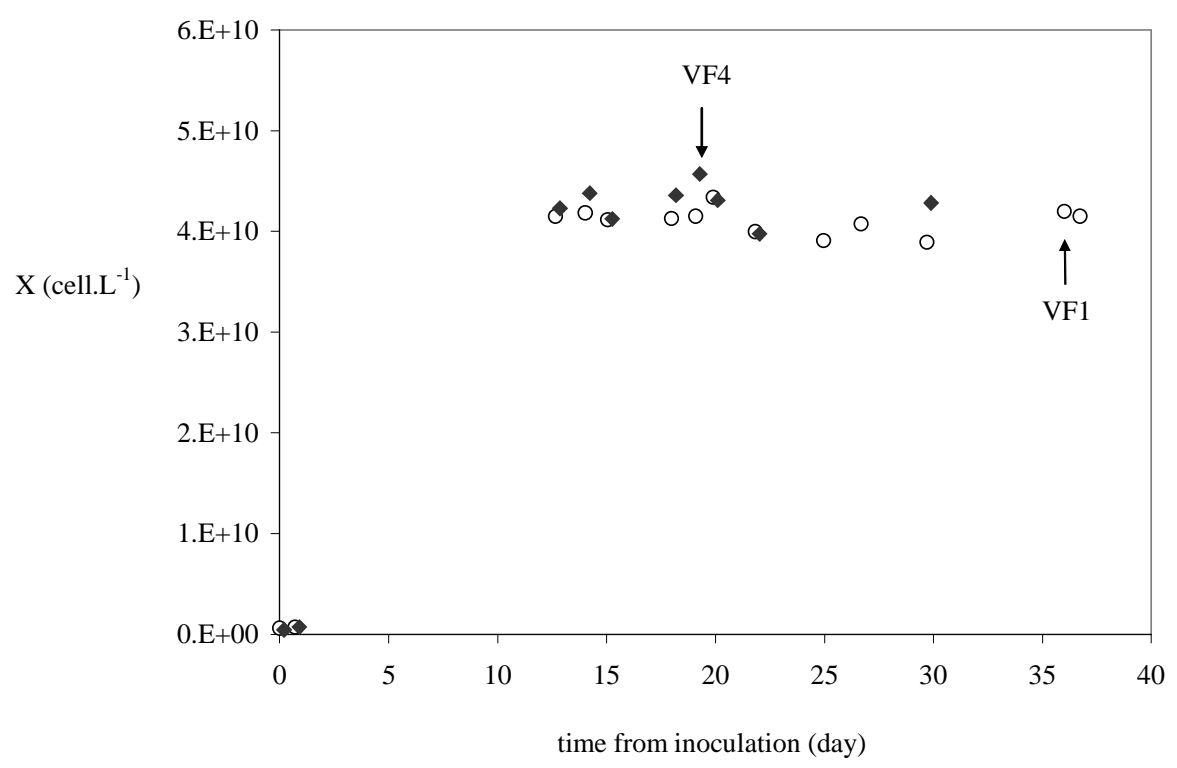


Figure 12




Figure 13
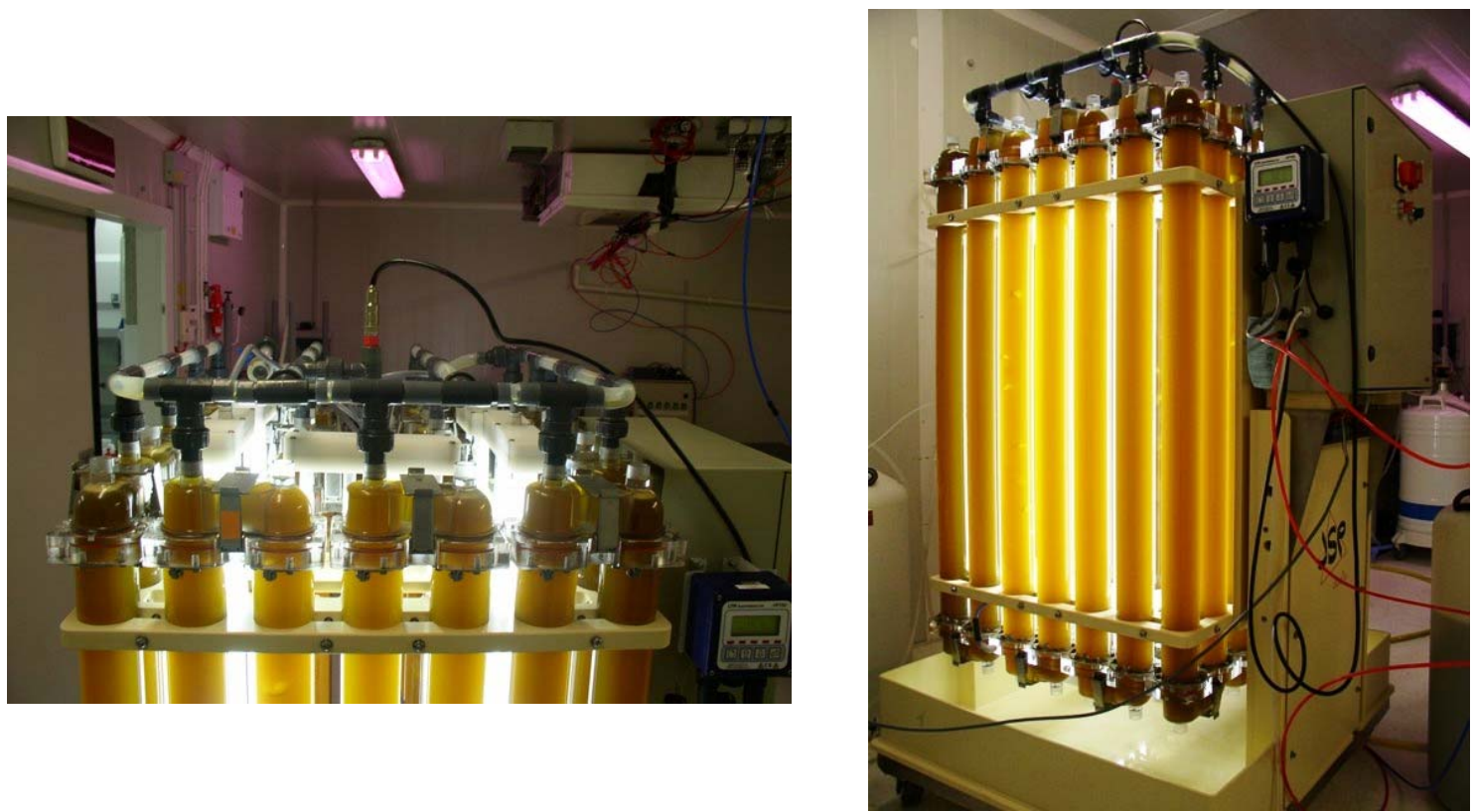
Table 1

Principal $\quad\left(\mathrm{FeCl}_{3}, 6 \mathrm{H}_{2} \mathrm{O}\right): 1.3 \mathrm{~g} ;\left(\mathrm{MnCl}_{2}, 4 \mathrm{H}_{2} \mathrm{O}\right): 0.36 \mathrm{~g}$; $\left(\mathrm{H}_{3} \mathrm{BO}_{3}\right)$ : $33.6 \mathrm{~g}$; $\left(\mathrm{Na}_{2}-\mathrm{EDTA}\right.$, elements: $\left.\quad 2 \mathrm{H}_{2} \mathrm{O}\right): 49.8 \mathrm{~g}$; $\left(\mathrm{NaH}_{2} \mathrm{PO}_{4}, 2 \mathrm{H}_{2} \mathrm{O}\right): 26$ g; $\left(\mathrm{NaNO}_{3}\right): 100 \mathrm{~g}$ $\left(\mathrm{ZnCl}_{2}\right): 0.021 \mathrm{~g} ;\left(\mathrm{CoCl}_{2}, 6 \mathrm{H}_{2} \mathrm{O}\right): 0.02 \mathrm{~g} ;\left(\left(\mathrm{NH}_{4}\right)_{6} \mathrm{Mo}_{7} \mathrm{O}_{4}^{2}, 4 \mathrm{H}_{2} \mathrm{O}\right): 0.009 \mathrm{~g}$; Metal: $\left(\mathrm{CuSO}_{4}, 5 \mathrm{H}_{2} \mathrm{O}\right): 0.02 \mathrm{~g}$

Vitamins: $\quad$ B1 (thiamine aneurine hydrochloride): $0.2 \mathrm{~g}$; B12 (cyanocobalamine): $0.01 \mathrm{~g}$ 
Table 2

\begin{tabular}{|c|c|c|c|c|c|c|c|}
\hline Air & $V F$ & $U_{C}$ & $\omega . U_{G}{ }^{v}$ & $t_{C}$ & $<t_{m} / t_{C}>$ & $\mathrm{D}_{\mathrm{ax}}$ & $R e_{L}$ \\
\hline sparger & $(-)$ & $\omega$ & $v$ & (s) & $(-)$ & $\left(\mathrm{m}^{2} \cdot \mathrm{s}^{-1}\right)$ & $(-)$ \\
\hline \multirow{3}{*}{$\mathrm{T}$} & 1 & 3.02 & 0.57 & $20.4-11.1$ & 11.7 & $0.12-0.21$ & $6.8 .10^{3}-1.3 .10^{4}$ \\
\hline & 4 & 0.27 & 0.33 & $64.7-39.6$ & 6.8 & $0.06-0.09$ & $2.1 .10^{3}-3.5 .10^{3}$ \\
\hline & 9 & 0.24 & 0.42 & $130.7-70.1$ & 4.0 & $0.05-0.07$ & $1.1 .10^{3}-2.10^{3}$ \\
\hline \multirow{3}{*}{ M } & 1 & 5.05 & 0.69 & $28.4-11.8$ & - & $0.06-0.14$ & $4.9 .10^{3}-1.2 .10^{5}$ \\
\hline & 4 & 1.08 & 0.64 & $113.5-44.1$ & 5.6 & $0.03-0.08$ & $1.2 .10^{3}-3.1 .10^{3}$ \\
\hline & 9 & 0.41 & 0.54 & $138.5-75.4$ & 3.7 & $0.04-0.08$ & $10^{3}-2.10^{3}$ \\
\hline
\end{tabular}


Table 3

\begin{tabular}{|c|c|c|c|c|c|}
\hline Air & $V F$ & $k_{L} a$ & & & \\
\hline sparge & & $\left.\beta\right|_{T W}$ & $\left.\delta\right|_{T W}$ & $\frac{\left(k_{L} a\right)_{C M}}{\left(k_{L} a\right)_{T W}}$ & $\frac{\left(k_{L} a\right)_{S W}}{\left(k_{L} a\right)_{T W}}$ \\
\hline$r$ & $(-)$ & & & & \\
\hline \multirow{3}{*}{$\mathrm{T}$} & 1 & 0.071 & 0.75 & $1.02-0.98$ & $1.05-1.03$ \\
\hline & 4 & 0.35 & 0.96 & $0.90-1.07$ & $0.84-1.10$ \\
\hline & 9 & 1.00 & 1.28 & $0.94-0.76$ & $0.99-0.88$ \\
\hline \multirow{3}{*}{ M } & 1 & 0.20 & 0.73 & $2.23-1.79$ & $2.09-1.76$ \\
\hline & 4 & 0.062 & 0.54 & $2.82-2.64$ & $3.16-2.60$ \\
\hline & 9 & 1.34 & 1.19 & $3.85 \rightarrow 2.25$ & $2.90 \rightarrow 2.56$ \\
\hline
\end{tabular}

